University of Zurich

Department of Economics

Working Paper Series

ISSN 1664-7041 (print)

ISSN 1664-705X (online)

Working Paper No. 199

\title{
Limited Commitment and the Demand for Money
}

Aleksander Berentsen, Samuel Huber and Alessandro Marchesiani

Revised version, February 2016 


\title{
Limited Commitment and the Demand for Money*
}

\author{
Aleksander Berentsen \\ University of Basel and Federal Reserve Bank of St. Louis \\ Samuel Huber \\ University of Basel \\ Alessandro Marchesiani
University of Bath
}

February 19, 2016

\begin{abstract}
Understanding money demand is important for our comprehension of macroeconomics and monetary policy. Its instability has made this a challenge. Common explications for the instability are financial regulations and financial innovations that shift the money demand function. We provide a complementary view by showing that a model where borrowers have limited commitment can significantly improve the fit between the theoretical money demand function and the data. Limited commitment can also explain why the ratio of credit to M1 is currently so low, despite that nominal interest rates are at their lowest recorded levels. In a low interest rate environment, incentives to default are high and so credit constraints bind tightly, which depresses credit activities.
\end{abstract}

JEL classification: D9, E4, E5.

Keywords: money demand, financial intermediation, limited commitment.

\section{Introduction}

Monetary theory suggests a stable negative relationship between money demand and nominal interest rates. However, for many countries this relationship is unstable and standard models fail to replicate it. For example, consider the empirical money demand curve for the United Kingdom displayed in Figure 1. We use the Lucas (2000) methodology to fit the curve and find that both specifications, the log-log and the semi-log specifications, fail to explain the flat parts of the money demand curve at low interest rates (between 2 and 4 percent) and high interest rates (between 6 and 12 percent). It

${ }^{*}$ The views expressed in this article are those of the authors and not necessarily those of the Federal Reserve Bank of St. Louis, the Federal Reserve System, or the FOMC. Any remaining errors are the authors' responsibility. Aleksander Berentsen is a professor of economics at the Department of Economic Theory, University of Basel. E-mail: aleksander.berentsen@unibas.ch. Samuel Huber is a research fellow at the Department of Economic Theory, University of Basel. E-mail: samuel_h@gmx.ch. Alessandro Marchesiani is a senior lecturer of economics at the Department of Economics, University of Bath. E-mail: marchesiani@gmail.com. 
also misses the sharp decrease in money demand as the opportunity cost of holding money increases from 4 to 6 percent. ${ }^{1}$

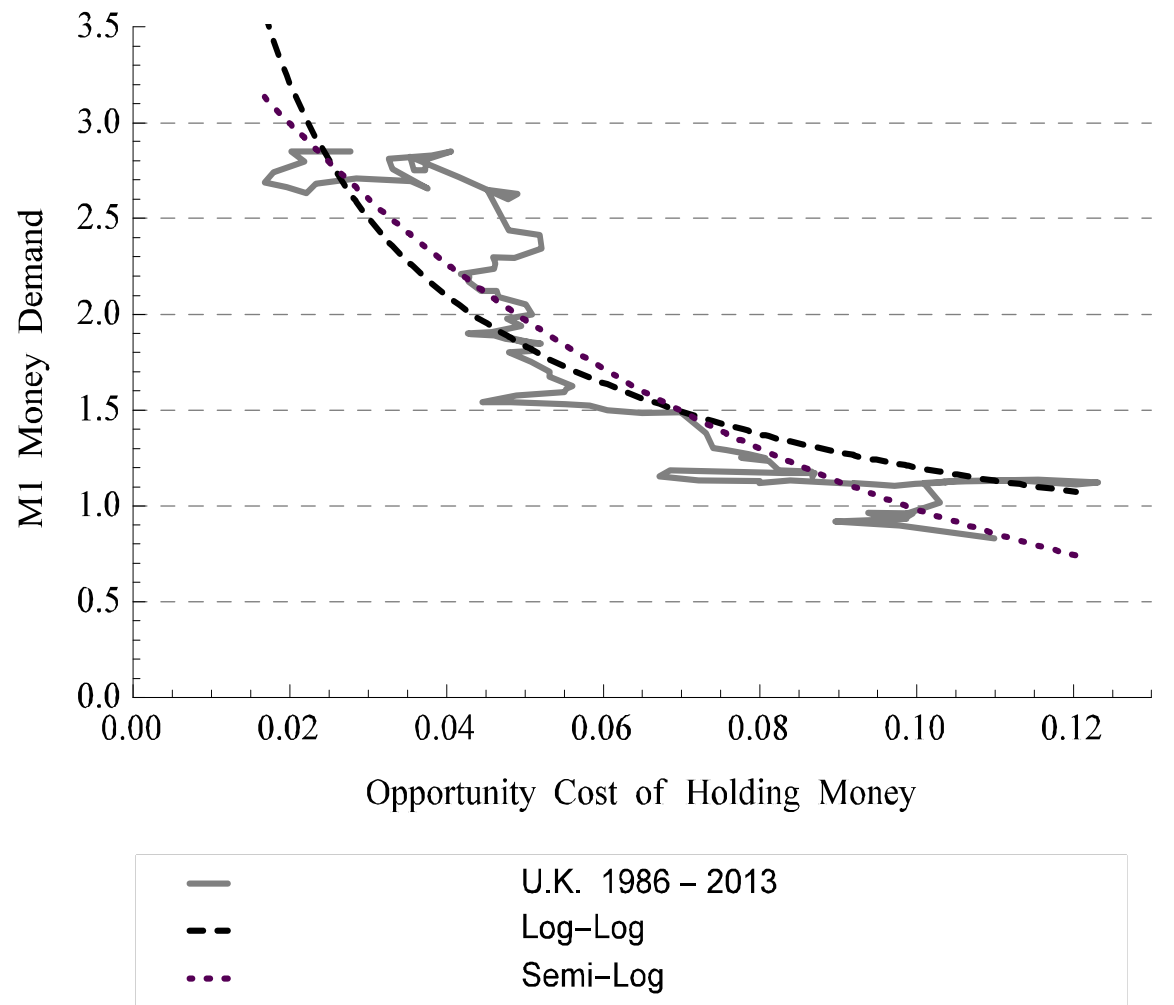

FiguRE 1: U.K. MONEY DEMAND

In this paper, we show that limited commitment can significantly improve the fit between the theoretical money demand curve and the data for several developed economies, compared to a model that assumes full commitment. We derive the demand for money in a microfounded monetary model and we analyze and calibrate it under two competing assumptions: Either agents can commit to repay their loans (full commitment) or they cannot (limited commitment). Limited commitment affects the shape of the money demand curve, because it gives rise to an endogenous borrowing constraint, which depends on monetary policy in an interesting way, as explained below.

We model limited commitment under the assumption that the punishment, for an agent who does not repay his loan, is permanent exclusion from borrowing and saving. ${ }^{2}$ A borrower, thus, faces a classic trade-off: The short-term utility gain from not repaying his debt versus the discounted sum of

\footnotetext{
${ }^{1}$ We measure money demand as the ratio of $\mathrm{M} 1$ to the nominal gross domestic product. For the opportunity cost of holding money, we use the U.K. 10-year government bond rate. We use this rate in order to have a comparable data set for our cross-country analysis, which is presented later on. As a cross-check, we have also used short-term rates if available. We do not report these results because they do not differ in an important way.

${ }^{2}$ We also derive results under a harsher punishment scheme, where default triggers autarky.
} 
utility losses from not being able to access financial markets in the future. Financial intermediaries understand this trade off and are only willing to provide credit up to an endogenous upper-bound. This bound is the largest loan size that a borrower will pay back voluntarily.

Figure 2 displays the empirical money demand curve for the United Kingdom and our best fit calibrations for the models with full commitment and limited commitment. The calibration under full commitment (the blue curve) generates comparable results to those using the Lucas methodology presented in Figure 1. It also shows that our model with limited commitment (the red curve) achieves a significantly better fit (see Table 2 for further statistical details).

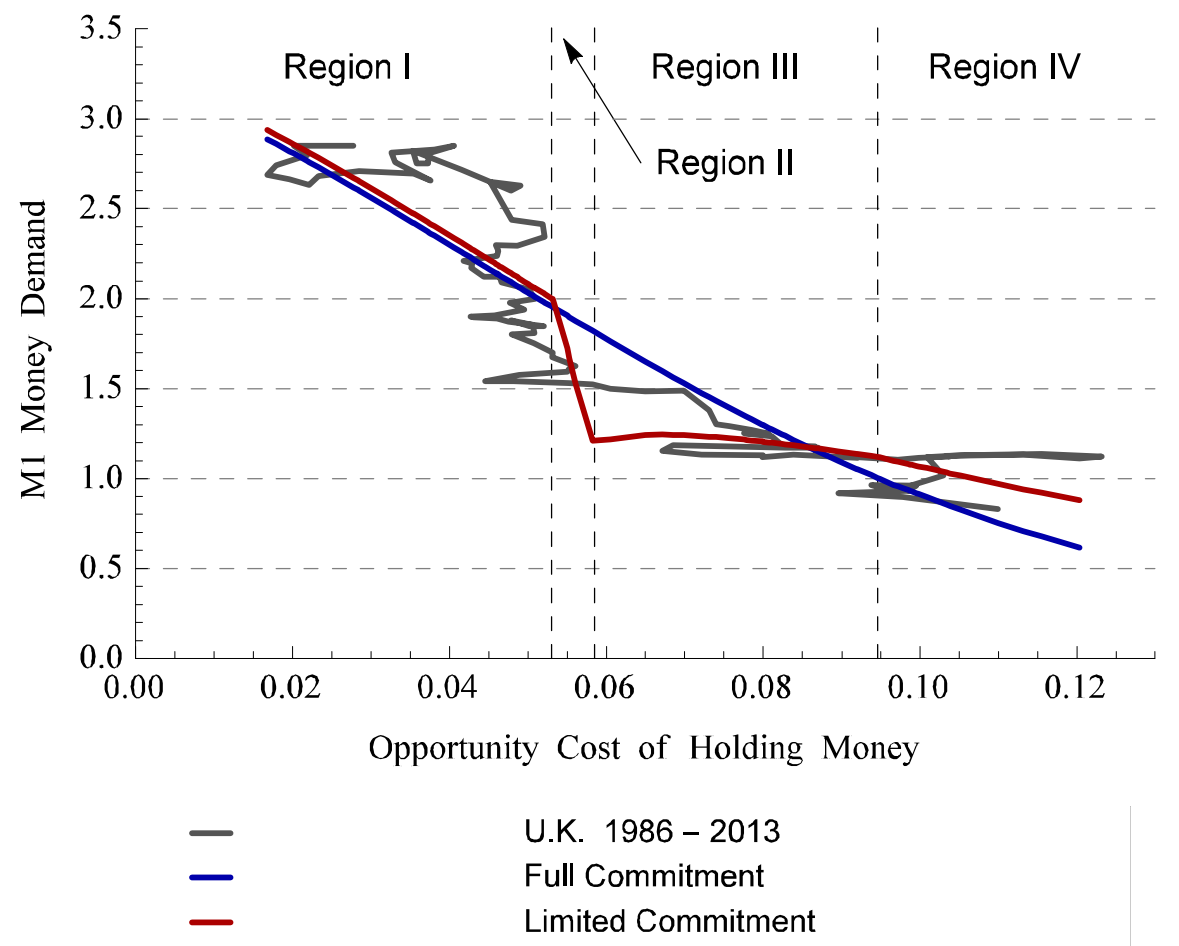

Figure 2: Best-fit CAlibration for the U.K.

With limited commitment, we identify four regions in our theory and display them in Figure 2. To understand these regions, note that there are two nominal interest rates in the model. One interest rate reflects the opportunity cost of holding money (captured by the U.K. 10-year government bond rate, in Figure 2) and the other one is the nominal interest rate at which agents can borrow (called the borrowing rate, which is not displayed in Figure 2).

Region I: For low opportunity costs of holding money (2 to 5.3 percent), the demand for money and the incentive to default are high. Furthermore, the borrowing constraint is tightly binding and there is almost no borrowing. As a consequence, the 'effective' demand for loans is very low, and since the supply of loans is inelastic, the equilibrium borrowing rate is very low. ${ }^{3}$ Region II: For low-to-

\footnotetext{
${ }^{3}$ Agents would like to get more credit at the prevailing low borrowing interest rate, but the borrowing constraint
} 
intermediate opportunity costs (5.3 to 5.8 percent), borrowing is rapidly increasing and the demand for money is decreasing. The reason is that an increase in the opportunity cost relaxes the borrowing constraint. Agents are able to borrow more and, for that reason, reduce their money holdings. Note that in this region, the 'effective' demand for loans continues to be small and the borrowing rate remains low. Region III: For intermediate opportunity costs (5.8 to 9.5 percent), borrowing and money demand are increasing simultaneously in the opportunity cost of holding money. In this region, the borrowing constraint is still binding and so an increase in the opportunity cost of holding money relaxes the borrowing constraint and increases borrowing. In contrast to Region II, the demand for money is increasing, because the interest rate at which agents can borrow is increasing faster than the opportunity cost of holding money. Region IV: For high opportunity costs (more than 9.5 percent), the incentive to default is low, because the opportunity cost of holding money is high. Consequently, borrowing is unconstrained. Furthermore, the demand for money is low and decreasing in the opportunity cost of holding money.

Our model implies that there is a positive correlation between nominal interest rates and credit activity. At first glance, this positive relationship appears counter-intuitive, as one might think that people want to borrow more when interest rates are low than when they are high. However, this intuition misses the fact that when interest rates are low credit constraints bind tightly and they receive less credit than they wish to obtain. For the United Kingdom, we observe a positive correlation between the ratio of credit to M1 and nominal interest rates of 0.93 for the private nonfinancial sector, while our model estimates a value of 0.89 . The positive correlation in the data suggests that limited commitment is indeed an issue for the United Kingdom. Models that assume full commitment of borrowers have a hard time to replicate such a strong positive correlation between nominal interest rates and credit activity.

Limited commitment can thus deliver an explanation for the "liquidity trap", as defined by Keynes:

"There is a possibility that after the rate of interest has fallen to a certain level, liquidity-preference may become virtually absolute in the sense that almost everyone prefers cash to holding a debt which yields so low a rate of interest." - Keynes (1936).

Our theory of limited commitment is consistent with the above quotation from Keynes (1936), where he observes that in a low interest rate environment agents do not want to hold debt. Our theory provides a rationale for this: In a low interest rate environment, savers do not want to hold debt (provide loans), because a borrower's incentive to default is high. It is also in accordance with the fact that although currently nominal interest rates are at their lowest recorded levels, credit activity is very low.

In order to find out how limited commitment affects money demand in other countries beside the United Kingdom, we also calibrate our model to Australia, Canada and the United States. Australia and Canada strengthen our conclusion that limited commitment can play an important role in explaining the behavior of money demand in the post-1980s period. For the United States, we do not find that limited commitment improves the fit compared to a model with full commitment. To understand this difference better, we study an alternative punishment scheme. Numerically, we

binds tightly, and so the 'effective' demand for credit is low. 
find that, under this alternative punishment scheme, the model can generate the same allocation as that of an economy where agents can fully commit to repay their debt.

\subsection{Literature review}

Understanding money demand is important for our comprehension of macroeconomics and monetary policy. Common explications for the instability of money demand are financial regulations and financial innovations that shift the money demand function (see the discussion further below). We provide a complementary view by showing that limited commitment can improve the fit between the theoretical money demand function and the data. Our attempt, here, is to explore how far one can get by focusing on limited commitment only. In reality, financial innovation, financial regulation, and limited commitment affect money demand simultaneously over time.

There are countless theoretical papers and many more empirical investigations on money demand. ${ }^{4}$ Perhaps, one of the reasons for this interest is the strong connection between money demand and the quantity theory of money. As Milton Friedman phrases it, "the quantity theory is in the first instance a theory of the demand for money" (Friedman, 1956, p.4). Hence, studying the behavior of the money demand function is important to understand the validity of the quantity theory, and its monetary policy implications. ${ }^{5}$

Meltzer (1963) was one of the first to document a stable relationship between the demand for money and interest rates using U.S. data. Lucas (1988) reviewed and confirmed, theoretically and empirically, Meltzer's (1963) results by extending the analysis to more recent data. The model estimated by Lucas (1988), however, does not work well after the mid-1980s, as we document above. In the literature, there are basically two approaches to address the instability of the money demand function. Some researchers construct models, where financial innovations affect the shape of the money demand function - without changing its definition. Others are working on more accurate definitions of money demand. Both approaches are related since the financial sector constantly innovates new money-like assets, and so the economics of monetary aggregates have changed considerably over time.

In an empirical work, Reynard's (2004) studies the effects of financial innovations on money demand. He observes that financial market participation increased substantially in the 1970s, and argues that this is the main determinant of the downward shift in the money demand function and its higher interest rate elasticity in the United States. Along the same lines, but in a calibrated model with a microfounded money demand curve, Berentsen et al. (2015) study how financial innovations affect the money demand curve in the United States. They assume full commitment, while in this paper we investigate the effects of limited commitment on the shape of the money demand curve.

Teles and Zhou (2005), Ireland (2009), and Lucas and Nicolini (2015) emphasize that the instability of money demand is due to a measurement problem. Deregulation of the financial sector in the

\footnotetext{
${ }^{4}$ Some early contributions to the money demand literature are Baumol (1952), Tobin (1956), Bailey (1956), and Meltzer (1963).

${ }^{5}$ According to the quantity theory of money, long-run inflation is correlated one-to-one with long-run money growth. Hence, if the quantity theory is valid, the central bank can target the inflation rate by simply choosing the appropriate rate of growth of money supply in the long-run. Recent works that focus on the validity of the quantity theory of money are, for example, Sargent and Surico (2011), Ireland (2015), and Teles et al. (2015).
} 
1980s and financial innovations in the 1990s have changed the role of M1, which is the monetary aggregate typically used to calculate the money demand function. For example, Teles and Zhou (2005) show that, prior to the 1980s, there was a clear distinction between M1 and M2. Assets assigned to M1 could be used in transactions, but yielded zero interest, while M2 assets yielded a positive interest, but were illiquid. Since the 1980s, some M2 assets could also be used for transactions. To circumvent this problem, Teles and Zhou (2005) split the data into two sub-periods, 1900-1979 and 1980-2003. They use M1 to measure the money demand for the first sub-period and the money zero maturity aggregate (MZM) for the second sub-period. ${ }^{6}$ They find that the long-run stability of the money demand is re-established when M1 is used for the period 1900-1979 and MZM for the period 1980-2003. Hence, they conclude that MZM is a better measure of the transaction demand for money after the 1980s. Ireland (2009) calculates the welfare cost of inflation in the United States for the period 1900-2006. Like Teles and Zhou, he splits the analysis into two sub-periods: 1900-1979 and 1980-2006. He then uses a new monetary aggregate (called M1RS) which is computed by adding the value of sweep funds to M1. ${ }^{7}$ He finds that the money demand function, measured by the M1RS-toGDP ratio, remains stable after 1980. Lucas and Nicolini (2015) construct a new monetary aggregate endogenously. They do so by modeling the role of currency, reserves, and bank deposits explicitly. Specifically, they adapt the model of Freeman and Kydland (2000) to rationalize the adding-up of different assets to form a new monetary aggregate, called NewM1. Using NewM1, they conclude that the money demand function in the United States is stable for the period 1915-2012. ${ }^{8}$ Our analysis is complementary to all studies discussed above, as none of them looks at the role of limited commitment on the shape of the money demand curve.

While writing this paper, we read several studies on the U.K. money demand. Most of these studies are empirical and date back, at least, to Brown (1939). More recent studies comprise, but are not limited to, Friedman and Schwartz (1982), Hendry and Ericsson (1991), and Drake (1996). Most of these studies are of an empirical nature and the main focus is parameter constancy, which is well documented in Judd and Scadding (1982) and Goldfeld and Sichel (1990). As pointed out by Ericsson (1998, p.299), "Non-constancy of estimated coefficients presents both economic and statistical difficulties in conducting any inferences from the empirical model." Thus, when the economic allocation changes over time, because constraints that are slack become binding, previously estimated models may become misspecified, and their nonconstancy is traced back to omitted variables.

Finally, our paper belongs to the so called "New Monetarist Economics" literature. In this literature, money is valuable, because of the existence of frictions that make it useful as a payment instrument (Lagos and Wright, 2005). Furthermore, financial intermediation of money (borrowing and saving) is essential, because it improves the allocation (Berentsen et al., 2007). An extensive and up-to-date discussion of this literature can be found in Williamson and Wright (2010), Nosal and Rocheteau (2011), and Lagos et al. (2015). Our paper is related to the many papers in that literature that study money demand and the welfare cost of inflation (e.g., Faig and Jerez, 2007, Craig and Rocheteau, 2008a and 2008b, Head et al., 2012, Liu et al., 2015, Wang, 2015). ${ }^{9}$ Our work

\footnotetext{
${ }^{6} \mathrm{MZM}$ is defined to be M2 minus small-denomination time deposits plus institutional money market mutual funds (MMMFs).

${ }^{7}$ See Dutkowsky and Cynamon (2003) and Cynamon et al. (2006a and 2006b) for a definition of M1RS.

${ }^{8}$ See Ireland (2015) and Mogliani and Urga (2015) for a detailed discussion of Lucas and Nicolini (2015).

${ }^{9}$ None of these papers has financial intermediation with limited commitment.
} 
is also related to the recent papers in this literature that study the acceptability of illiquid assets (e.g., Lagos and Rocheteau, 2008, Lester et al., 2012, and Hu and Rocheteau, 2013).

\section{Environment}

The basic setup follows Berentsen et al. (2015). The main difference is that we relax the full commitment assumption for financial transactions and study the implication of limited commitment on the shape of the money demand function. ${ }^{10}$ There is a measure $[0,1]$ of agents who live forever in discrete time. In each period, there are three markets that open and close sequentially. In the first market, agents can borrow and deposit money; in the second market, production and consumption of a specialized good takes place; in the third market, credit contracts are settled and a general good is produced and consumed. We call these markets money market, goods market, and centralized market, respectively. All goods are perfectly perishable in the sense that their value goes to zero if they are not consumed in the market where they are produced. This assumption rules out any form of commodity money. Finally, we assume that all goods are perfectly divisible.

At the beginning of each period, agents receive two idiosyncratic shocks. A preference shock determines whether an agent can consume or produce in the goods market: he can produce but not consume with probability $n$, or he can consume but not produce with probability $1-n$. We refer to producers and consumers as sellers and buyers, respectively. An entry shock determines whether an agent participates in the money market: he has access to the money market with probability $\sigma$, or he does not have access with probability $1-\sigma$. We refer to agents who have access as active, and to agents who do not as passive.

In the goods market, buyers and sellers are matched according to the following reduced-form matching function, $\mathcal{M}(n, 1-n)$, where $\mathcal{M}$ denotes the number of matches in a period. We assume that $\mathcal{M}(n, 1-n)$ has constant returns to scale, and is continuous and increasing with respect to each of its arguments. The probability that a buyer is matched with a seller in the goods market is denoted by $\delta(n)=\mathcal{M}(n, 1-n)(1-n)^{-1}$, while the probability that a seller is matched with a buyer is denoted by $\delta^{s}(n)=\delta(n)(1-n) n^{-1}$. To simplify on notation, we shorten $\delta(n)$ and $\delta^{s}(n)$ as $\delta$ and $\delta^{s}$, respectively.

A buyer enjoys utility $u(q)$ from consuming $q$ units of the specialized good, where $u(q)$ satisfies the following properties: $u^{\prime}(q)>0, u^{\prime \prime}(q)<0, u^{\prime}(0)=\infty$, and $u^{\prime}(\infty)=0$. A seller incurs a disutility $c(q)=q$ from producing $q$ units of the specialized good. There is no record-keeping technology, and agents are anonymous in this market. This implies that a buyer's promise to pay for his purchased goods in the future is not credible, hence trades must be settled immediately. Consequently, a medium of exchange is needed for transactions.

The centralized market is a frictionless market where agents can produce and consume a general good. No medium of exchange is needed for transactions in this market. Agents receive utility $U(x)$ from consuming $x$ units of the general good, where $U(x)$ has the following properties: $U^{\prime}(x)$, $-U^{\prime \prime}(x)>0, U^{\prime}(0)=\infty$, and $U^{\prime}(\infty)=0$. They produce the general good according to a linear

\footnotetext{
${ }^{10}$ The focus of Berentsen et al. (2015) is to investigate how financial innovations such as the introduction of money market deposit accounts affected the demand for money in the United States. Throughout the paper, Berentsen et al. (2015) assume full commitment of borrowers via banks.
} 
technology that transforms $h$ hours of work into $h$ units of the general good, suffering disutility $h$. Agents cannot communicate with each other, and their actions are not publicly observed in this market. Agents discount between, but not within, periods. Let $\beta \in(0,1)$ be the discount factor between two consecutive periods and let $r \equiv(1-\beta) \beta^{-1}$ denote the real interest rate.

There exists a perfectly storable, divisible, intrinsically useless object in the economy, called money. Its supply evolves according to the law of motion $M_{t+1}=\gamma M_{t}$, where $\gamma$ denotes the gross growth rate of money, and $M_{t}$ the stock of money in period $t$. Also, there exists a central bank which injects (withdraws) money through a lump-sum transfer $T_{t}$ to all agents in the centralized market, where $T_{t}=M_{t+1}-M_{t}=(\gamma-1) M_{t}$. To economize on notation, we shorten $t+1$ and $t-1$ as +1 and -1 , respectively.

Perfectly competitive financial intermediaries, or banks, take deposits and make loans in the money market. Agents access this market after they learn their type (buyer or seller), but before they enter the goods market. Buyers and sellers have different liquidity needs in the money market: Buyers need more money than they have since they want to consume in the goods market, while sellers have excess money holdings since they can only produce. This generates a role for banks who can reallocate money from those who need less (sellers) to those who need more (buyers). Deposit and loan contracts are redeemed at the end of each period, in the centralized market. Banks also operate a costless, record-keeping technology of all financial transactions, but they cannot enforce loan repayment in the centralized market. Because of the record-keeping technology, banks perfectly know each agent's identity and credit history, but not his trade history. Finally, banks are perfectly competitive, which implies that the money market rate $i_{m}$ is the same for depositors and lenders.

Finally, monetary policy consists of choosing a constant money growth rate $\gamma$. Let $i$ be the nominal interest rate on a one-period bond acquired in the centralized market that pays the principal plus the nominal interest rate $i$ in the next period's centralized market. ${ }^{11}$ The interest rate $i$ on this bond constitutes the opportunity cost of holding money across periods. It is well known that in this class of models, the Fisher equation holds: that is, $i=(\gamma-\beta) / \beta$. From the Fisher equation, it is evident that the central bank controls the nominal interest rate $i$, and we will therefore express many of our equations in terms of $i$, instead of $\gamma$. Furthermore, we sometimes refer to $i$ as the policy rate to make the connection to monetary policy more evident.

\section{Agents' Decisions}

We now describe the agent's decision problem in each market. To do so, we proceed backwards from the centralized market to the money market.

The centralized market. In the centralized market, agents play different roles. First, they can consume and produce a general good, $x$. Second, they redeem their financial contracts: A seller receives money plus interest from his deposits, while a buyer pays back his loan plus interest. For now, we assume buyers always honor their obligations in the centralized market. Later in the paper, we relax this assumption and derive conditions such that loan repayment is voluntary under different

\footnotetext{
${ }^{11}$ We do not model the trading of such a bond explicitly. Nevertheless, we can price it by using the Fisher equation.
} 
punishment schemes. Agents receive a lump-sum money transfer from the central bank, and choose the amount of money to take into the next period.

Let $V_{3}(m, \ell, d)$ be the value function of an agent entering the centralized market with $m$ units of money, $\ell$ units of loans, and $d$ units of deposits. Then, the agent's problem in the centralized market is

$$
V_{3}(m, \ell, d)=\max _{x, h, m_{+1}} U(x)-h+\beta V_{1}\left(m_{+1}\right),
$$

subject to the budget constraint

$$
x+\phi m_{+1}=h+\phi m+\phi T+\phi\left(1+i_{m}\right) d-\phi\left(1+i_{m}\right) \ell
$$

where $\phi$ denotes the price of money in terms of the general good, and $h$ denotes hours of work. A standard result in this literature is that the choice of $m_{+1}$ is independent of $m$. This result comes from the quasi-linearity assumption in the consumption function and implies that the distribution of money holdings is degenerate at the end of each period. This makes the analysis analytically tractable.

The goods market. Let $(q, z)$ be the terms of trade agreed within a meeting in the goods market, where $q$ is the amount of goods produced by the seller and $z$ is the amount of money exchanged in the meeting. The terms of trade $(q, z)$ are determined using the Kalai, or proportional, solution to the bargaining problem, which is as follows: ${ }^{12}$

$$
\begin{aligned}
(q, z) & =\arg \max u(q)-\phi z \\
\text { s.t. } u(q)-\phi z & =\theta[u(q)-q] \quad \text { and } \quad z \leq m,
\end{aligned}
$$

where $\theta$ denotes the bargaining power of a buyer. The equality constraint is the Kalai constraint, which determines how a buyer and a seller split the total surplus from trade, $u(q)-q$. The buyer receives the fraction $\theta$ of this surplus. ${ }^{13}$ The inequality constraint is the buyer's cash constraint according to which a buyer cannot offer the seller more money than he has. If the buyer's cash constraint binds (i.e., $m=z$ ), then the solution to the above problem is

$$
\phi m=g(q) \equiv \theta q+(1-\theta) u(q) .
$$

If the buyer's constraint does not bind (i.e., $m>z$ ), then $q=q^{*}$, and $z=m^{*}=\frac{g\left(q^{*}\right)}{\phi}$, where $q^{*}$ solves $u^{\prime}\left(q^{*}\right)=g^{\prime}\left(q^{*}\right)$.

The value function of a buyer entering the goods market with $m$ units of money and $\ell$ units of loans is

$$
V_{2}^{b}(m, \ell, 0)=\delta\left[u(q)+V_{3}(m-z, \ell, 0)\right]+(1-\delta) V_{3}(m, \ell, 0) .
$$

\footnotetext{
${ }^{12}$ Alternative trading protocols include Nash bargaining and price taking. One of the desired properties of the Kalai solution, as opposed to the Nash solution, is that it is strongly monotonic in the sense that no agent is made worse off from an expansion of the bargaining surplus (Aruoba et al., 2007).

${ }^{13}$ This can be seen from the Kalai constraint in the bargaining problem. A buyer's surplus from trade is given by the instantaneous utility from consumption, $u(q)$, minus the real value of money he gives to the seller, $\phi z$. This is equal to a share, $\theta$, of the total surplus, $u(q)-q$.
} 
With probability $\delta$, he has a match with a seller in the goods market, in which case he enjoys utility $u(q)$ from consuming $q$ units of the specialized good. The possibility to consume reduces his continuation value by $z$ units of money. With probability $1-\delta$, he has no match in the goods market and waits for the centralized market to open. Note that active buyers never deposit money, so $d=0$.

The value function of a seller in the goods market is

$$
V_{2}^{s}(m, 0, d)=\delta\left[-q+V_{3}(m+z, 0, d)\right]+(1-\delta) V_{3}(m, 0, d) .
$$

With probability $\delta$, a seller has a match and incurs a disutility $c(q)=q$ in exchange for $z$ units of money. Note that active sellers never borrow money; i.e., $\ell=0$.

The money market. In the money market, an agent can deposit or borrow money at the bank. The money market opens at the beginning of each period after agents learn their type (buyer or seller). Before the money market opens, agents also learn whether they will have access to this market or not. After agents have deposited and borrowed money, the money market closes.

Let $V_{1}^{b}(m)$ be the value function of an active buyer entering the money market with $m$ units of money, and let $V_{1}^{s}(m)$ be that of an active seller. Also, let $V_{2}^{b}(m, 0)$ and $V_{2}^{s}(m, 0)$ be the respective value functions of a passive buyer and a passive seller, entering the goods market. Since passive agents do not participate in the money market, they enter the goods market with no credit contract; i.e., $\ell=d=0$. Then, the value function of an agent at the beginning of each period is

$$
V_{1}(m)=\sigma\left[(1-n) V_{1}^{b}(m)+n V_{1}^{s}(m)\right]+(1-\sigma)\left[(1-n) V_{2}^{b}(m, 0)+n V_{2}^{s}(m, 0)\right] .
$$

An agent in the money market is an active buyer with probability $\sigma(1-n)$, an active seller with probability $\sigma n$, a passive buyer with probability $(1-\sigma)(1-n)$, and a passive seller with probability $(1-\sigma) n$. A passive agent can neither lend nor borrow money at the bank. Hence, he just waits for the goods market to open.

Loan repayment in the centralized market is voluntary in the sense that a buyer repays his loan if, and only if, it is profitable for him to do so. Sellers have no obligation in the centralized market (they receive money from the bank), so default is not an issue for them. In order to create an incentive for the buyer to repay his debt, we assume some form of punishment for those who default. In particular, we assume permanent exclusion from the money market for defaulters. Note that banks perfectly know the identity of the defaulters and can (will) always refuse to trade with them. Hence, permanent exclusion from the money market can be implemented. We will study an alternative punishment scheme later.

A buyer who decides to default on his debt enjoys a benefit and suffers a cost for doing so. On the one hand, he has to work fewer hours in the centralized market, since he does not have to repay his debt plus interest. On the other hand, he will consume less in all future periods, since he can no longer borrow or lend money, and thus cannot insure himself against adverse liquidity shocks. If the cost associated with the punishment is higher than the benefit, a deviation is not profitable, and the buyer honors his obligation.

In what follows, we denote all quantities associated with a defaulter by a tilde " ", and all quantities associated with an active agent by a hat “^”. Quantities without a superscript refer to passive agents. Also, let $\phi \bar{\ell}$ denote the borrowing limit, which is the maximum amount of real 
borrowing that is compatible with voluntary repayment. A bank will never lend more than $\phi \bar{\ell}$ to a buyer, since this would trigger a strategic default in the centralized market. The conditions that make debt repayment voluntarily in a steady state are derived in the Appendix, and we rewrite them in the following ${ }^{14}$

Lemma 1 A buyer repays his loan if, and only if,

$$
\phi \ell \leq \phi \bar{\ell}
$$

with

$$
\begin{aligned}
\phi \bar{\ell}= & \frac{i[g(\tilde{q})-g(q)]}{r\left(1+i_{m}\right)} \\
& +\frac{(1-n) \delta}{r\left(1+i_{m}\right)}\{\sigma[u(\hat{q})-g(\hat{q})]+(1-\sigma)[u(q)-g(q)]-[u(\tilde{q})-g(\tilde{q})]\},
\end{aligned}
$$

where $\tilde{q}$ satisfies

$$
i=(1-n) \delta\left[\frac{u^{\prime}(\tilde{q})}{g^{\prime}(\tilde{q})}-1\right] .
$$

The endogenous borrowing limit $\phi \bar{\ell}$ has an intuitive interpretation. The first term on the righthand side reflects the utility benefit of not repaying the loan. The second term is the utility loss of having no access to financial markets in the future. To see this, note that $\sigma[u(\hat{q})-g(\hat{q})]+$ $(1-\sigma)[u(q)-g(q)]$ is the expected utility surplus of having access to the money market in a given period, and $[u(\tilde{q})-g(\tilde{q})]$ is the expected utility surplus from having no access.

To derive some comparative static results for the borrowing limit $\phi \bar{\ell}$, it is convenient to use (7) to rewrite (6) as follows:

$$
\phi \bar{\ell}=\frac{(1-n) \delta}{r\left(1+i_{m}\right)} \Omega
$$

where

$$
\Omega \equiv\left[u^{\prime}(\tilde{q})-g^{\prime}(\tilde{q})\right][g(\tilde{q})-g(q)] / g^{\prime}(\tilde{q})+\sigma[u(\hat{q})-g(\hat{q})]+(1-\sigma)[u(q)-g(q)]-[u(\tilde{q})-g(\tilde{q})] .
$$

A change in the policy rate $i$ affects the borrowing limit $\phi \bar{\ell}$ through changes of the consumption quantities $q, \tilde{q}$ and $\hat{q}$, and changes of the money market rate $i_{m}$. These general equilibrium effects are highly nonlinear and it is difficult to derive analytical results. ${ }^{15}$ Nevertheless, we can deduce the following partial equilibrium effects: An increase in the real interest rate $r$ decreases the borrowing limit, because it reduces the discounted utilities from future surpluses. An increase in the matching probability of the goods market $\delta$ increases the borrowing limit, because it increases the probability of trading and hence expected future utilities. An increase in the probability of becoming a buyer $1-n$ increases the borrowing limit, because it makes it more important to have access to the money market. Finally, an exogenous increase in the money market rate $i_{m}$ reduces $\phi \bar{\ell}$, because it makes it more costly to use the money market.

\footnotetext{
${ }^{14}$ From the Fisher equation, $i=(\gamma-\beta) / \beta$. Hence, we can express (1) in terms of $i$ or $\gamma$.

${ }^{15}$ See Figure 6 for more explanations.
} 
At this point, we can write an agent's maximization problem in the money market. An active buyer's problem in the money market is

$$
V_{1}^{b}(m)=\max _{\ell} V_{2}^{b}(m+\ell, \ell)
$$

subject to the borrowing constraint (5). It is easy to check that active buyers borrow in the money market, since they have high liquidity needs (they want to consume in the goods market). The real amount of money a buyer can borrow may or may not be constrained depending on which equilibrium the economy ends up with. An active seller's problem in the money market is

$$
V_{1}^{s}(m)=\max _{d} V_{2}^{s}(m-d, d) \quad \text { s.t. } \quad m-d \geq 0,
$$

where the constraint in (9) means that a seller cannot deposit more money than the amount he has. Unlike buyers, sellers deposit money and do not borrow in the money market, since they have low liquidity needs in the sense that they do not consume in the goods market.

\section{Monetary Steady State Equilibrium}

Throughout the paper, we focus on monetary steady state equilibria where all real quantities are constant and money is valued. ${ }^{16}$ In any monetary steady state equilibrium, the marginal value of money satisfies the following expression (see the Appendix for the derivation):

$$
i=\sigma\left\{(1-n) \delta\left[\frac{u^{\prime}(\hat{q})}{g^{\prime}(\hat{q})}-1\right]+n i_{m}\right\}+(1-\sigma)(1-n) \delta\left[\frac{u^{\prime}(q)}{g^{\prime}(q)}-1\right] .
$$

This expression is derived from the first-order condition for the choice of money holdings in the centralized market. It requires that the marginal cost of acquiring a unit of money (the nominal interest rate $i$ ) is equal to the expected marginal benefit of spending it: With probability $\sigma(1-n)$, the agent becomes an active buyer, and the expected utility from spending it is $\delta\left[\frac{u^{\prime}(\hat{q})}{g^{\prime}(\hat{q})}-1\right]$; with probability $\sigma n$, the agent becomes an active seller and can earn the money market rate $i_{m}$; with probability $(1-\sigma)(1-n)$, the agents becomes a passive buyer, and obtains the expected utility $\delta\left[\frac{u^{\prime}(q)}{g^{\prime}(q)}-1\right]$ from spending it; and with probability $(1-\sigma) n$, he becomes a passive seller who gets no utility.

There are two critical constraints in the model that can be used to characterize the monetary equilibrium allocation as a function of the policy rate $i$ : The borrowing constraint (5) and the seller's cash constraint (9). Let $\lambda_{\Phi}$ be the Lagrange multiplier on the buyer's borrowing constraint (5), and $\lambda_{s}$ the Lagrange multiplier on the seller's cash constraint in (9). Then, depending on the values of $\lambda_{\Phi}$ and $\lambda_{s}$, we can characterize several types of equilibria and derive the ranges of $i$ for which the types exist. The proofs of all Propositions that follow are in the Appendix.

\footnotetext{
${ }^{16}$ In this class of models, there is always a steady state equilibrium where money is not valued and not used in exchange.
} 


\subsection{Types}

In a type-0 equilibrium, active sellers do not deposit all their money $\left(\lambda_{s}=0\right)$, and the buyer's borrowing constraint is not binding $\left(\lambda_{\Phi}=0\right)$. A type-0 equilibrium is characterized by the following

Proposition 1 A type-0 equilibrium is a list $\left\{i_{m}, \hat{q}, \tilde{q}, q, \phi \ell, \phi \bar{\ell}\right\}$ satisfying equations (6), (7), (10), and

$$
\begin{aligned}
g(\hat{q}) & =g(q)+\phi \ell \\
i_{m} & =\delta\left[\frac{u^{\prime}(\hat{q})}{g^{\prime}(\hat{q})}-1\right] \\
i_{m} & =0 .
\end{aligned}
$$

Equations (6) and (7) are derived and explained in Lemma 1 and refer to the borrowing limit of an active buyer and the consumption quantity of a defaulter, respectively. Equation (10) equates the marginal cost of holding money to the marginal expected benefit of spending it and is explained above. Equation (11) requires that the real amount of money that an active buyer spends in the goods market, $g(\hat{q})$, is equal to the real amount of money spent as a passive buyer, $g(q)$, plus the real loan an active buyer obtains from the bank, $\phi \ell$. This equation is derived from the active buyer's budget constraint and immediately implies that active buyers never consume less than passive buyers $(\hat{q} \geq q)$. Equation (12) is the first-order condition for the choice of borrowing in the money market. Active buyers are not borrowing-constrained in a type-0 equilibrium, which means that they borrow exactly up to the point where the marginal cost of borrowing an additional unit of money (left-hand side) is equal to the marginal benefit (right-hand side). Also, since $i_{m}=0$, active buyers consume the first-best quantity of goods $\left(\hat{q}=q^{*}\right)$. In contrast, from (10), passive buyers consume an inefficient quantity $\left(q<q^{*}\right)$ unless $i=0$. Finally, for $\lambda_{s}=0$ to hold, sellers must be indifferent between depositing their money and not depositing it. This can be the case if, and only if, (13) holds.

In a type-I or a type-II equilibrium, active sellers do not deposit all their money $\left(\lambda_{s}=0\right)$ and the borrowing constraint is binding $\left(\lambda_{\Phi}>0\right)$. As for the type- 0 equilibrium, this is only possible if $i_{m}=0$. A type-I or a type-II equilibrium is characterized by the following

Proposition 2 A type-I or a type-II equilibrium is a list $\left\{i_{m}, \hat{q}, \tilde{q}, q, \phi \ell, \phi \bar{\ell}\right\}$ satisfying (6), (7), (10), and

$$
\begin{aligned}
g(\hat{q}) & =g(q)+\phi \ell \\
\phi \ell & =\phi \bar{\ell}, \\
i_{m} & =0 .
\end{aligned}
$$

All equations in Proposition 2 have the same meaning as their counterparts in Proposition 1, except for (15) which differs from (12). In a type-I or a type-II equilibrium, an active buyer is borrowing-constrained. The bank knows that $\phi \ell>\phi \bar{\ell}$ will trigger a default, hence it lends the buyer exactly $\phi \bar{\ell}$. In this case, the marginal value of borrowing is higher than its marginal cost. Consequently, the first-order condition for the choice of borrowing (12) is replaced by the borrowing constraint (15). 
The system of equations in Proposition 2 admits at least one solution which is the straightforward solution $\hat{q}=q=\tilde{q}$. To see this, assume $\hat{q}=q$. Then, from (14), it holds that $\phi \ell=0$. Furthermore, (10) collapses to (7), implying that $\tilde{q}=\hat{q}$. This means that the two terms on the right-hand side of (6) are both zero, and, thus, $\phi \bar{\ell}=0$. Therefore, we conclude that the above-mentioned quantities are equilibrium quantities, and we call this solution the type-I equilibrium. We cannot show analytically that other solutions exists for equations (6), (7), (10), and (14)-(16). However, we identify numerically a solution with $q^{*}>\hat{q}>q$ and $\phi \ell=\phi \bar{\ell}>0$, where $q^{*}$ solves $u^{\prime}\left(q^{*}\right)=g^{\prime}\left(q^{*}\right)$. We call this solution the type-II equilibrium.

To summarize, in a type-I equilibrium, the money market interest rate is zero $\left(i_{m}=0\right)$, borrowing is constrained and the borrowing limit is equal to zero $(\phi \ell=\phi \bar{\ell}=0)$, and both active and passive buyers consume the same inefficient quantity of goods in the goods market $\left(\hat{q}=q<q^{*}\right)$. In a type-II equilibrium, the money market interest rate is zero $\left(i_{m}=0\right)$, borrowing is constrained and the borrowing limit is strictly positive $(\phi \ell=\phi \bar{\ell}>0)$, and active buyers consume more than passive buyers in the goods market $\left(q^{*}>\hat{q}>q\right)$.

In a type-III equilibrium, active sellers deposit all their money at the bank $\left(\lambda_{s}>0\right)$, and the active buyer's borrowing constraint is binding $\left(\lambda_{\Phi}>0\right)$. A type-III equilibrium is characterized by the following

Proposition 3 A type-III equilibrium is a list $\left\{i_{m}, \hat{q}, \tilde{q}, q, \phi \ell, \phi \bar{\ell}\right\}$ satisfying (6), (7), (10), and

$$
\begin{aligned}
g(\hat{q}) & =g(q)+\phi \ell, \\
\phi \ell & =\phi \bar{\ell}, \\
g(q) & =(1-n) g(\hat{q}) .
\end{aligned}
$$

All the equations in Proposition 3 have the same meaning as their counterparts in Proposition 2, except that (16) is now replaced by (19). Equation (19) is the money market clearing condition which is derived under the condition that sellers supply all their money. It holds in this type of equilibrium, because $i_{m}>0$. It does not hold in Proposition 2, because sellers do not deposit all their money.

In a type-IV equilibrium, active sellers deposit all their money $\left(\lambda_{s}>0\right)$, and the buyer's borrowing constraint is not binding $\left(\lambda_{\Phi}=0\right)$. A type-IV equilibrium is characterized by the following

Proposition 4 A type-IV equilibrium is a list $\left\{i_{m}, \hat{q}, \tilde{q}, q, \phi \ell, \phi \bar{\ell}\right\}$ satisfying (6), (7), (10), and

$$
\begin{aligned}
g(\hat{q}) & =g(q)+\phi \ell, \\
i_{m} & =\delta\left[\frac{u^{\prime}(\hat{q})}{g^{\prime}(\hat{q})}-1\right], \\
g(q) & =(1-n) g(\hat{q}) .
\end{aligned}
$$

All the equations in Proposition 4 have the same meaning as the respective equations in Proposition 3, except that (18) is now replaced by (21). The meaning of equation (21) is the following. Unlike in a type-III equilibrium, active buyers are not borrowing-constrained in a type-IV equilibrium, which means that they borrow exactly up to the point where the marginal cost of borrowing an additional unit of money (left-hand side) is equal to the marginal benefit (right-hand side). Consequently, we replace the borrowing constraint (18) with the first-order condition for the choice of borrowing (21). 


\subsection{Sequence}

We find the following sequence of equilibria as the nominal interest rate $i$ increases from 0 to infinity: type-0, type-I, type-II, type-III, and type-IV. Let $i_{0}$ be the value of $i$ that separates the type-0 from the type-I equilibrium, $i_{1}$ be the value of $i$ that separates the type-I from the type-II equilibrium, $i_{2}$ the value of $i$ that separates the type-II from the type-III equilibrium, and $i_{3}$ the value of $i$ that separates the type-III from the type-IV equilibrium. This sequence of equilibria is summarized in the following table.

TABle 1: Sequence of EQUilibria

\begin{tabular}{ccccccc}
\hline \hline Region & Equilibrium & $i$ & $\lambda_{\Phi}$ & $\lambda_{s}$ & $i_{m}$ & Real borrowing \\
\hline & type-0 & $i=i_{0}=0$ & $\lambda_{\Phi}=0$ & $\lambda_{s}=0$ & $i_{m}=0$ & $\phi \ell=\phi \bar{\ell}=0$ \\
I & type-I & $i_{0} \leq i \leq i_{1}$ & $\lambda_{\Phi}>0$ & $\lambda_{s}=0$ & $i_{m}=0$ & $\phi \ell=\phi \bar{\ell}=0$ \\
II & type-II & $i_{1} \leq i \leq i_{2}$ & $\lambda_{\Phi}>0$ & $\lambda_{s}=0$ & $i_{m}=0$ & $\phi \ell=\phi \bar{\ell}>0$ \\
III & type-III & $i_{2} \leq i \leq i_{3}$ & $\lambda_{\Phi}>0$ & $\lambda_{s}>0$ & $i_{m}>0$ & $\phi \ell=\phi \bar{\ell}>0$ \\
IV & type-IV & $i_{3} \leq i$ & $\lambda_{\Phi}=0$ & $\lambda_{s}>0$ & $i_{m}>0$ & $\phi \ell<\phi \bar{\ell}>0$ \\
\hline
\end{tabular}

The critical values are derived by identifying at which values of $i$ the different types of equilibria generate the same allocation. First, numerically we find that the type- 0 equilibrium only exists when $i=0 .{ }^{17}$ Furthermore, the allocation in the type- 0 and type-I equilibria are identical at $i=0$. Hence, we find that $i_{0}=0$ is the value of $i$ that separates these two types of equilibria. Second, $i_{1}$ is the value of $i$ such that $\phi \bar{\ell}=0$ in a type-II equilibrium. Consequently, the type-I and the type-II allocations are identical at $i=i_{1}$. Third, $i_{2}$ is the value of $i$ that solves $i_{m}=0$ in a type-III equilibrium. Consequently, the type-II and the type-III allocations are identical at $i=i_{2}$. Fourth, $i_{3}$ is the value of $i$ such that $i_{m}=\delta\left[u^{\prime}(\hat{q}) / g^{\prime}(\hat{q})-1\right]$ in a type-III equilibrium. Consequently, the type-III and the type-IV allocations are identical at $i=i_{3}$.

Finally, note that in Figure 2 in the introduction we have identified regions I, II, III, and IV. These regions are characterized by the type-I, type-II, type-III, and type-IV equilibria, respectively. Also, the dotted vertical lines correspond to the critical values $i_{1}, i_{2}$, and $i_{3}$, respectively. In Figure 2, they are calculated according to our best-fit calibration, which we will present further below.

\section{Discussion}

In this section, we discuss the implications of partial access to borrowing and saving, compare the allocations under full and limited commitment, and analyze the model under an alternative punishment scheme. Finally, we look at the liquidity trap.

\subsection{Full access vs partial access}

Before discussing the role of partial access on consumed quantities, let us derive the money demand function. To do this, let us define the real output in the goods market and in the centralized market.

\footnotetext{
${ }^{17}$ We cannot formally prove this statement. Theoretically, there can be multiple equilibria where type- 0 and type-I equilibria co-exist. However, we have not found such multiplicity in any of our numerical calculations.
} 
The real output in the goods market is $Y_{G M}=(1-n) \delta[\sigma \phi \hat{m}+(1-\sigma) \phi m]$, where $\phi \hat{m}=g(\hat{q})$ and $\phi M_{-1}=\phi m=g(q)$, while the real output in the centralized market is $Y_{C M}=A$ for $U(x)=A \log (x)$. Accordingly, the total real output of the economy is $Y=Y_{G M}+Y_{C M}$, and the model-implied money demand is

$$
\mathcal{M D}=\frac{\phi M_{-1}}{Y}=\frac{g(q)}{A+(1-n) \delta[\sigma g(\hat{q})+(1-\sigma) g(q)]}
$$

Note that, from the quantity theory of money, money demand is defined to be the inverse of the velocity of money; i.e., $\mathcal{M D}=1 / V=M_{-1} / P Y$. Using $P=1 / \phi$, we obtain (23).

The two top diagrams in Figure 3 display the quantities of specialized goods consumed by an active buyer, $\hat{q}$, a passive buyer, $q$, and a deviator, $\tilde{q}$, as a function of the opportunity cost of holding money, $i$. The two bottom diagrams display money demand, $\mathcal{M D}$, as a function of $i$. The diagrams on the left-hand side refer to the case where all agents have access to the money market $(\sigma=1)$. In this case, there are no passive agents, and a buyer can either be active, in which case he will consume $\hat{q}$, or be banned from trading in the money market (because he defaulted), in which case he will consume $\tilde{q}$. The diagrams on the right-hand side refer to the case where access to the money market is partial $(0<\sigma<1)$. We also display money demand for $\sigma=0$, where the money market is inactive and consumption is the same for all buyers. 

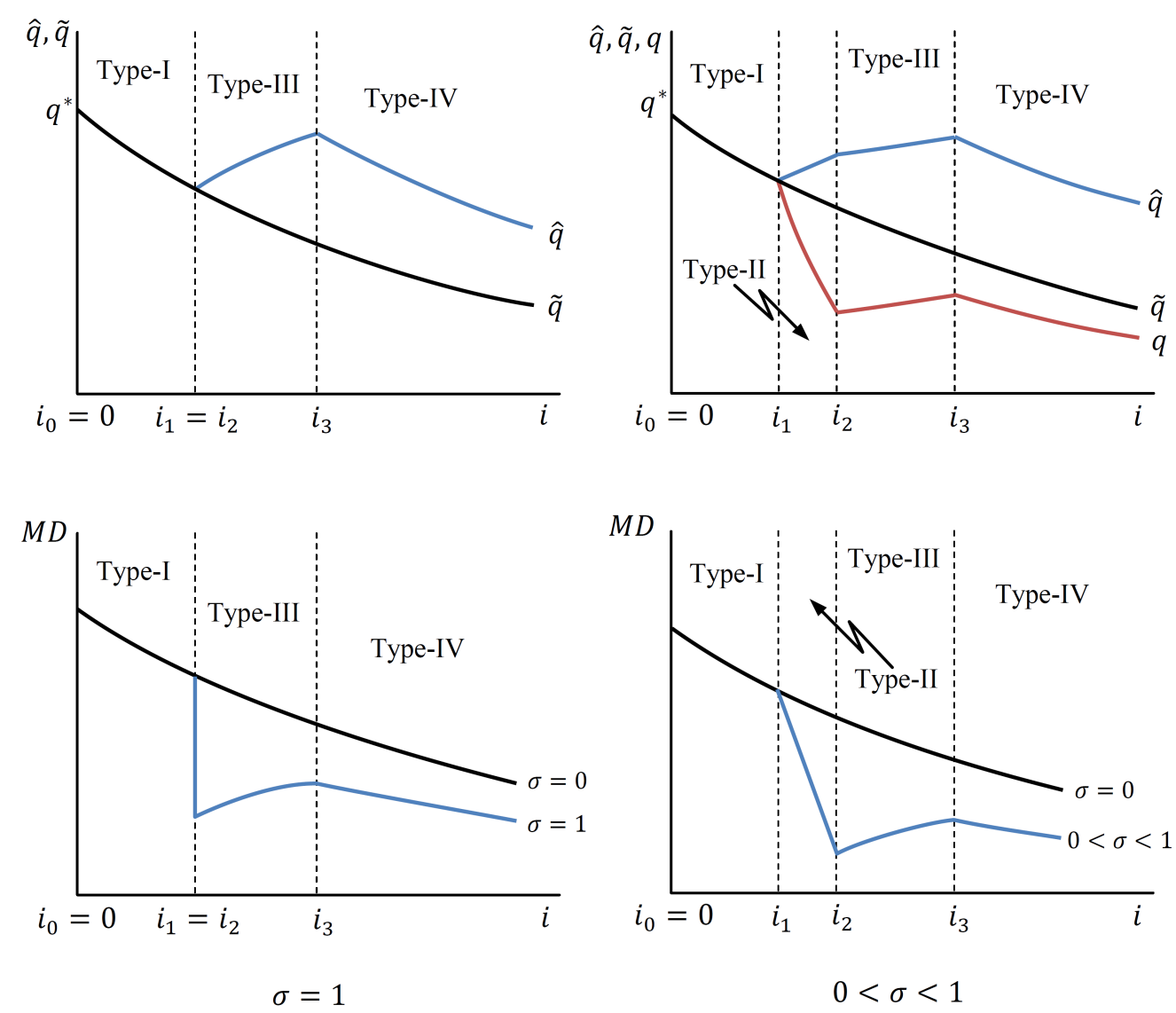

Figure 3: Consumed quantities And Money Demand

Let us look at the limited participation case; i.e., at the top-right diagram in Figure 3. In a type-I equilibrium $\left(0 \leq i \leq i_{1}\right)$, there is no credit since $\phi \ell=\phi \bar{\ell}=0$. Accordingly, the quantities of goods consumed by active and passive agents are equal. Furthermore, they equal the quantity consumed by a deviator and are decreasing in $i$. In this regime, money demand is high and decreasing in $i$. It is high, because there is no credit available and so agents want to hold large quantities of money in order to self-insure against the liquidity shocks (buyer/seller shock). Money demand is decreasing in $i$, because $i$ is the opportunity cost of holding money. This is the classical real balance effect which is sometimes also referred to as the inflation tax effect.

In the type-II equilibrium $\left(i_{1} \leq i \leq i_{2}\right)$, borrowing is strictly positive and constrained, since $\phi \ell=\phi \bar{\ell}>0$. Consequently, $\hat{q}>q .{ }^{18}$ Consumption of active agents is increasing in $i$, while

\footnotetext{
${ }^{18}$ Active buyers always have the option of not trading in the money market, since trades are voluntary. This means that $\hat{q} \geq \tilde{q}$ in any equilibrium. Note, however, that $q$ can be smaller or larger that $\tilde{q}$; in Figure 3 we show the case where $q<\tilde{q}$.
} 
consumption of passive agents is decreasing. The reason why $\hat{q}$ is increasing is that the borrowing constraint relaxes as $i$ increases. This allows active agents to borrow and consume more. Consumption of passive agents, $q$, is falling for the following reason: As $i$ increases, more credit becomes available, and so the demand for money falls. To restore equilibrium, the value of money falls. This reduces the purchasing power of the passive agents (active agents can undo this by obtaining more credit) and so they consume less. In this region, money demand is rapidly decreasing in $i$ for two reasons. First as in region I, because the opportunity cost of holding money $i$ increases. Second, cheap credit is available. Thus, the opportunity to borrow provides insurance against liquidity shocks (buyer/seller and active/passive shocks) and so agents reduce their demand for money relative to a situation where no such opportunity exists.

In the type-III equilibrium $\left(i_{2} \leq i \leq i_{3}\right)$, there is also constrained borrowing, since since $\phi \ell=$ $\phi \bar{\ell}>0$. Consumption quantities of active and passive agents are increasing in $i$. As in the type-II equilibrium, $\hat{q}$ is increasing because the borrowing constraint relaxes as $i$ increases, and so active agents can borrow more. In contrast to the type-II equilibrium, $q$ is also increasing. The reason is that in this region, the marginal borrowing cost, as represented by the borrowing interest rate $i_{m}$, increases rapidly. In fact, $i_{m}$ is increasing faster than $i$. Because $i_{m}$ increase faster than $i$, the demand for money increases. To restore the equilibrium, the value of money increases, which explains why the consumption of passive agents, $q$, is also increasing in $i$.

Finally, for $i \geq i_{3}$, the type-IV equilibrium exists, where borrowing is unconstrained, and the consumption of active and passive agents is decreasing in $i$. Consumption quantities are decreasing here, because the value of money decreases when the opportunity cost of money increases.

Let us now look at the full participation case; i.e., $\sigma=1$. If all agents can participate in the money market, the type-I equilibrium occurs if $0 \leq i \leq i_{1}=i_{2} \cdot{ }^{19}$ When the marginal cost of holding money is sufficiently low $\left(0 \leq i \leq i_{1}=i_{2}\right)$, the benefit of participating in the money market is small, since agents can cheaply insure themselves against liquidity shocks by holding money. Consequently, an active buyer's incentive to default is high and so $\phi \ell=\phi \bar{\ell}=0$. In this region, the allocation is the same as the one of an economy without a money market. When $\sigma=1$, the type-II equilibrium is degenerate since $i_{1}=i_{2}$. The type-III equilibrium occurs for $i_{1}=i_{2} \leq i \leq i_{3}$. In this case, $\phi \bar{\ell}$ and $\hat{q}$ are increasing in $i$. The reason for this is that an increase in the opportunity cost of holding money relaxes the borrowing constraint, allowing the active buyer to borrow more, and thus to consume more. Finally, the type-IV equilibrium occurs for $i \geq i_{3}$. In this case, borrowing is unconstrained and the quantities of goods consumed by active buyers and defaulting buyers are decreasing in $i$ because of the standard inflation-tax argument.

\subsection{Full commitment vs limited commitment}

In Berentsen et al. (2015), we derive the same model under the assumption of full commitment. In that paper, we find that the following sequence of equilibria prevails: For $0 \leq i \leq i_{F}$, prices and quantities are described by the type- 0 equilibrium and for $i_{F} \leq i$, prices and quantities are described by the type-IV equilibrium. The critical value $i_{F}$ is the value of $i$ such that $\hat{q}=q^{*}$ in a type-IV

\footnotetext{
${ }^{19}$ Note that, with full access, all the critical interest rates (i.e. $i_{0}, i_{1}, i_{2}$, and $i_{3}$ ) can be calculated in the same way we did with partial access $(0<\sigma<1)$. However, due to the fact that now $\sigma=1$, the numerical values are obviously different from those obtained with partial access.
} 
equilibrium. It becomes clear, that the underlying assumption about commitment strongly affects the equilibrium quantities, which is shown in Figure 4 below.

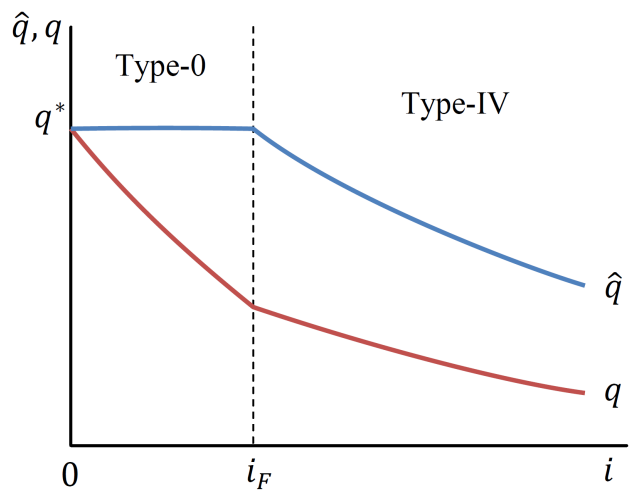

Full commitment

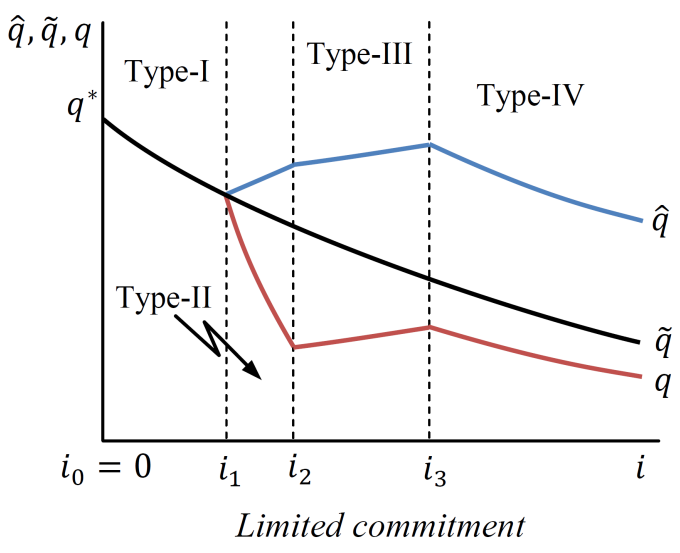

Limited commitment

Figure 4: Full Commitment vs. Limited Commitment

The diagram on the left-hand side of Figure 4 shows the consumed quantities under full commitment, while the diagram on the right-hand side displays the allocation under limited commitment. We have discussed the latter further above. One can show that for $i<i_{3}$ the consumed quantities under limited commitment are lower than the ones under full commitment, since agents are borrowing-constrained. For $i \geq i_{3}$, the quantities are the same. With full commitment, in the type-0 equilibrium, $q<\hat{q}=q^{*}$. In this region, the demand for loans is small, because the opportunity cost of holding money is small and so buyers bring enough real balances into the period to guarantee an almost efficient consumption quantity. Active buyers then use the money market to borrow additional funds so that they can consume $\hat{q}=q^{*}$. One can also show that the borrowing rate $i_{m}$ is zero. The reason is that demand for loans is relatively small and sellers offer all their money in the market for $i_{m}>0$. Market clearing then requires that $i_{m}=0$, and sellers are indifferent to how much money they offer. In equilibrium, they simply offer the amount requested by the buyers.

Finally, note that the type-IV equilibrium is identical under full and limited commitment. The reason is that the borrowing constraint is nonbinding under limited commitment.

\subsection{Autarky punishment}

So far, we have assumed that defaulters are excluded from borrowing and lending in the money market. We now propose an alternative punishment scheme in which defaulters are permanently excluded from both the money market and the goods market. Let us call this type of punishment autarky punishment.

There is a crucial difference between the two schemes. This is best understood if we set the opportunity cost of holding money equal to zero $(i=0)$. In this case, agents can without cost selfinsure against the liquidity shocks that are present in the model, since holding money across periods 
is costless. Consequently, the baseline punishment of excluding agents from financial markets has no bite at $i=0$. In contrast, the autarky punishment is still effective at $i=0$, since access to the goods market is valuable at $i=0$.

A further difference is that under the baseline punishment scheme, the punishment is increasing in $i=0$ (at least for low values of $i$ ), while for the autarky punishment scheme, the punishment is decreasing in $i$. The reason is that, for the baseline punishment scheme, self-insurance becomes more costly as $i$ increases. In contrast, for the autarky punishment scheme, the expected surplus from trading in the goods market is decreasing in $i$. The two punishments have, therefore, very different properties.

In the Appendix, we show how the autarky punishment scheme can be implemented, and we derive the following

Lemma 2 Under an autarky punishment scheme, a buyer's real borrowing constraint is

$$
\begin{aligned}
\phi \ell \leq & -\frac{i}{r\left(1+i_{m}\right)} g(q) \\
& +\frac{(1-n) \delta}{r\left(1+i_{m}\right)}\{\sigma[u(\hat{q})-\hat{q}]+(1-\sigma)[u(q)-q]\} .
\end{aligned}
$$

Under an autarky punishment scheme, we identify the following sequence of equilibria: type-0, type-II, type-III, and type-IV.$^{20}$ Unlike the previous punishment, a buyer's borrowing constraint is now nonbinding for low enough policy rates $\left(0 \leq i \leq i_{0}\right)$, and the economy is in the type- 0 equilibrium in this region. This is, as discussed above, because the surplus from trading in the goods market is strictly positive even for low interest rates. Consequently, agents honor their obligations even in a low interest rate environment. Note that the expected surplus from trade in the goods market $\sigma[u(\hat{q})-\hat{q}]+(1-\sigma)[u(q)-q]$ is always negatively related to the opportunity cost of holding money, and is maximized at $i=0$.

This establishes an important difference between the two punishment schemes: With autarky punishment, consumed quantities are always decreasing in $i$, while they can increase in $i$ for the baseline punishment case (compare the right-hand diagrams in Figure 4 and 5). We have explained the reason for this further above.

\footnotetext{
${ }^{20}$ For completeness, this is not the only sequence we identified. Numerically, we find that the type-II and type-III equilibria shrink as agents become more patient, or trading frictions become less severe. At some point, the type-II and type-III equilibria disappear and the sequence type-0-type-IV arises. In this case, the allocation under full commitment and that under limited commitment with autarky punishment are identical.
} 


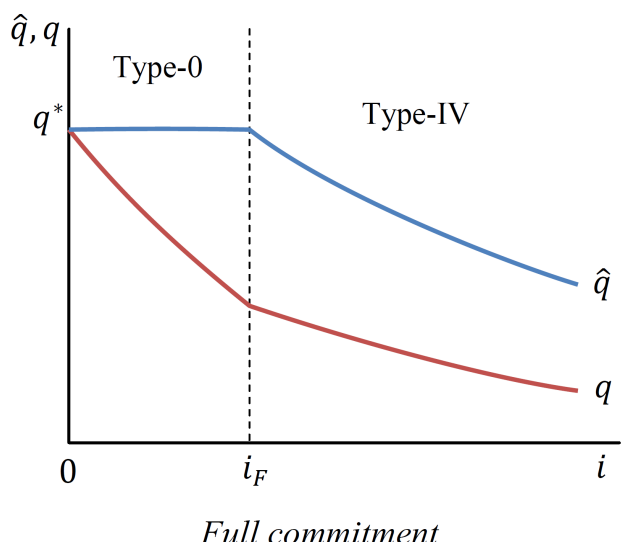

Figure 5: Full Commitment vis. Autarky

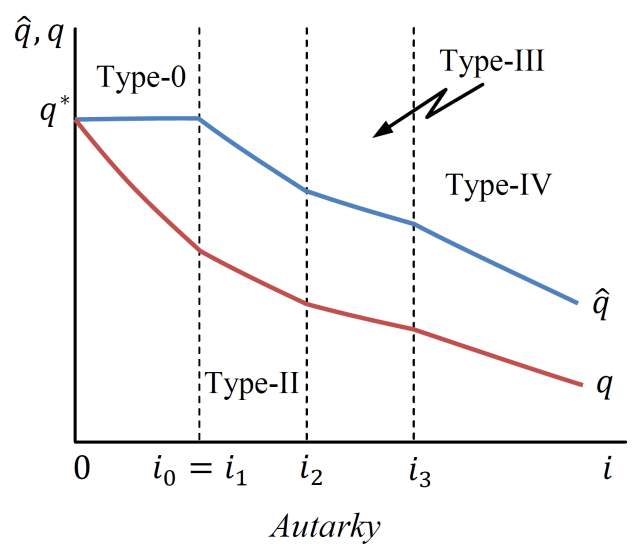

In Figure 5, we compare the quantities of goods consumed by active and passive buyers as a function of the opportunity cost of holding money under full commitment and under autarky. It becomes clear that under the autarky punishment scheme, the allocation gets much closer to the full commitment case compared to our baseline punishment scheme. Since under autarky the punishment is always costly, financial intermediaries grant loans for any $i>0$. Consequently, the type-I equilibrium ceases to exist. Finally, it is quite evident that if we were to introduce even more severe punishments for default, the allocation under limited commitment would approach the one under full commitment.

\subsection{Liquidity trap}

In the introduction, we discussed the liquidity trap and we quoted Keynes (1936) as saying that in a low interest rate environment agents are not willing to provide loans. We identified limited commitment as the source of this phenomenon. 


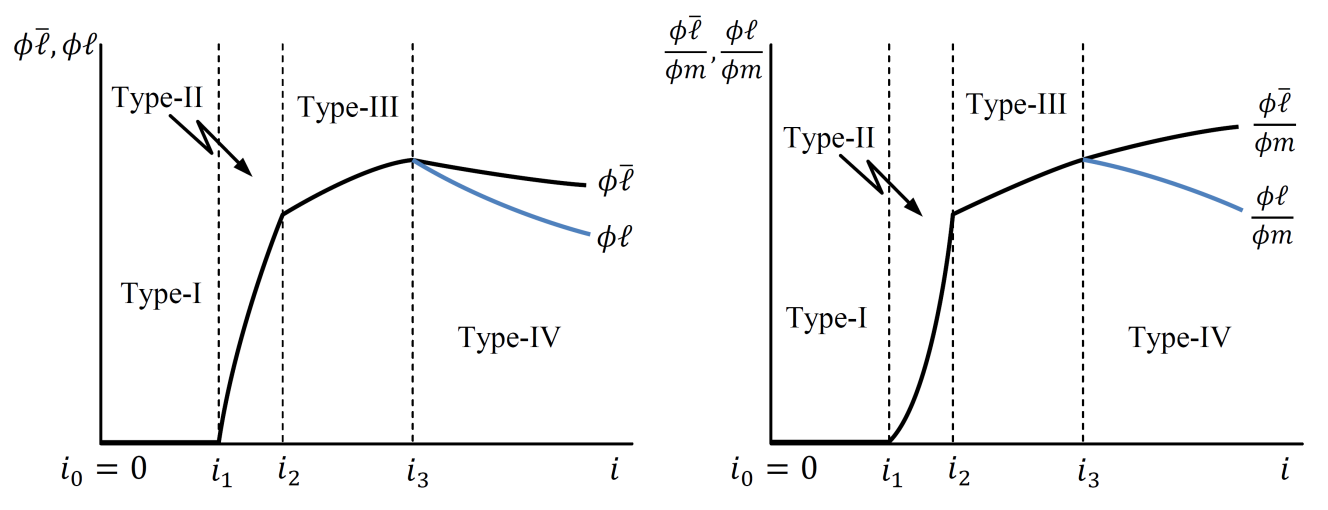

Figure 6: BORROWING

Figure 6 displays the liquidity trap and the positive correlation of the ratio of credit to M1 (see the curve $\frac{\phi \ell}{\phi m}$ ) with the nominal interest rate. First, for low interest rates, no credit is available in the region labelled Type-I (the liquid trap). ${ }^{21}$ It is clear by now that limited commitment is the cause for this scarcity of credit. Second, there is a strong positive correlation in the regions labelled Type-II and Type-III. The reason is also limited commitment, since in these regions the borrowing constraint (see the curve $\frac{\phi \tilde{\ell}}{\phi m}$ ) is binding. It is relaxed as the $i$ increases and so more credit becomes available.

Note that the baseline punishment scheme is crucial for this result. Further above, we have seen that with the autarky punishment borrowing and lending takes place even for low interest rates. This means that no liquidity trap exists under the autarky punishment scheme.

Figure 6 displays borrowing as a function of the opportunity cost of holding money $i$ with partial access $(0<\sigma<1)$ under the baseline punishment scheme. The diagram on the left-hand side displays real borrowing $\phi \ell$ and the real borrowing constraint $\phi \bar{\ell}$. For $0 \leq i \leq i_{1}$, there is no borrowing and the money market shuts down no matter what the value of $\sigma$ is. ${ }^{22}$ For $i_{1} \leq i \leq i_{2}$, borrowing is constrained and rapidly increasing. It is rapidly increasing, because the increase in $i$ relaxes the borrowing constraint. For $i_{2} \leq i \leq i_{3}$, borrowing is constrained and increasing, but with a smaller slope than in the region before. The reason is that the borrowing interest rate, $i_{m}$, is increasing and increasing faster than $i$. For $i \geq i_{3}$, borrowing is unconstrained and decreasing in $i$. Here, the real balance effect makes borrowing more expensive and so agents want to borrow less.

The diagram on the right-hand side displays the ratio $\phi \ell / \phi m$ and the ratio $\phi \bar{\ell} / \phi m$. The ratio $\phi \ell / \phi m$ measures the ratio of credit to M1. As discussed in the introduction, the correlation between $\phi \ell / \phi m$ and $i$ is positive up to and including region III (whenever the borrowing constraint binds). Furthermore, since in these experiments we hold the quantity of money constant, the model also predicts a positive correlation between $\ell$ and $i$ for small opportunity costs (see the diagram on the

\footnotetext{
${ }^{21}$ In reality, there is still credit available if the borrower has collateral.

${ }^{22}$ In the theoretical model, there is no borrowing in this region, because we assume that all agents have limited commitment. In reality, there will be still some borrowing, because some credit is collateralized.
} 
right-hand side). Finally, we also observe a positive correlation between the real borrowing and $i$ in these regions (see the left-hand-side diagram).

\section{Quantitative Analysis}

Hereafter, we calibrate our model to see how well our theoretical money demand function fits the empirical money demand curve for the United Kingdom. In particular, we compare the fit of our limited commitment model to the fit of the same model under full commitment, and to the fits of the two empirical methods proposed by Lucas $(2000) .{ }^{23}$

Lucas (2000) explores the log-log and the semi-log specifications to fit the money demand curve. Under the log-log (semi-log) specification money demand satisfies $\mathcal{M D}_{L L}=A i^{-\alpha}\left(\mathcal{M D}_{S L}=A e^{-\alpha i}\right)$. For both, we estimate the unknown parameters $A$ and $\alpha$ by minimizing the sum of squared differences between the model and the data.

The calibration of our models is a bit more evolved and we proceed as follows. First, we set a period length to one year and annualize all data accordingly. Second, we assume the following functional forms, $u(q)=q^{1-\alpha} /(1-\alpha), U(x)=A \log (x)$, and $c(q)=q$. Third, we follow Kiyotaki and Wright (1993) and choose a matching function of the form $\mathcal{M}(B, S)=B S /(B+S)$, where $B=1-n$ is the measure of buyers, and $S=n$ is the measure of sellers.

Then, we identify the following set of parameters: (i) preference parameters $\beta, A$, and $\alpha$; (ii) technology parameters $n$ and $\sigma$; (iii) the bargaining weight, $\theta$; and (iv) the policy parameter, $i$. The parameters are identified using quarterly U.K. data, from 1986 to $2013 .^{24}$

The policy parameter $i=0.062$ matches the average annual yield on government bonds with a maturity of 10 years. $^{25}$ The preference parameter $\beta=(1+r)^{-1}=0.968$ is chosen such that the real interest rate in the model, $r=0.034$, replicates the empirical one, which is measured as the difference between the average annual yield on government bonds with a maturity of 10 years and the annual change in the consumer price index. The technology parameter $n$ is set to maximize the number of matches; i.e., $n=0.5$.

The remaining unknown parameters $A, \alpha, \sigma$, and $\theta$, are identified by minimizing the sum of squared differences between the model-implied and the observed money demand, and by matching the goods market mark-up simultaneously. The demand for money in the model is given by (23), while the goods market mark-up is the weighted average of the real money holdings divided by the production cost in this market, $\mu=\sigma g(\hat{q}) / c(\hat{q})+(1-\sigma) g(q) / c(q)-1$. The target value for the goods market mark-up of $\mu=0.15$ is borrowed from Martins et al. (1996). The calibration and simulation results for our model with full commitment and limited commitment, as well as for the two specifications by Lucas (2000), are shown in Table 2.

\footnotetext{
${ }^{23}$ Recall that under full commitment for $0<i<i_{F}$, the type- 0 equilibrium exists, and for $i>i_{F}$, the type-IV equilibrium exists. The demand for money under full commitment still satisfies (23).

${ }^{24}$ The data source is provided in the Appendix. For consistency, all data used in this paper is obtained from the Federal Reserve Bank of St. Louis FRED database. As the quarterly time series for M1 for the U.K. is only available for the post-1985 period, we focus on this sample period in the entire paper.

${ }^{25}$ Related studies work with the AAA rate, which represents the yield on corporate bonds with a remaining maturity of 20 years. See, for instance, Berentsen et al. (2011, 2014, and 2015) and Aruoba et al. (2011). However, since we perform a cross-country analysis, we decided to use the yield on 10-year government bonds in order to have a comparable data set.
} 
Table 2: Calibration and simulation Results for the U.K. ${ }^{a}$

\begin{tabular}{llllllllllll}
\hline \hline Method & $A$ & $\alpha$ & $\theta$ & $\sigma$ & $i_{F}$ & $i_{1}$ & $i_{2}$ & $i_{3}$ & $s_{G M}$ & $\Delta$ & $\sum$ sq. diff. \\
\hline Log-Log & 0.30 & 0.61 & - & - & - & - & - & - & - & 0.091 & 11.4 \\
Semi-Log & 3.96 & 13.9 & - & - & - & - & - & - & - & 0.135 & 7.07 \\
Full Com. & 0.06 & 0.17 & 0.76 & 0.000 & 0.000 & - & - & - & 0.43 & 0.134 & 7.39 \\
Limited Com. & 0.06 & 0.17 & 0.75 & 0.625 & - & 0.053 & 0.058 & 0.093 & 0.50 & 0.121 & 5.94 \\
\hline
\end{tabular}

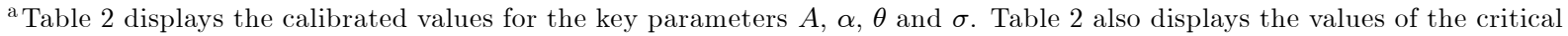
interest rates $i_{F}, i_{1}, i_{2}$ and $i_{3}$; the goods market share on total output, $s_{G M}$; and the welfare cost of inflation, $\Delta$. The table also shows the sum of squared differences $(\Sigma$ sq. diff) between the model-implied money demand and the data.

Table 2 shows that our model with limited commitment succeeds best in replicating the data; i.e., it yields the smallest sum of squared differences between the theoretical money demand curve and the data. For limited commitment, the resulting welfare cost of inflation is around 12 percent, which is of similar magnitude to the values obtained under the other specifications. ${ }^{26}$ The welfare cost of inflation in the United Kingdom is much higher than, say, in the United States. The reason is that money demand in the United Kingdom is larger than that in the United States by roughly a factor of 10 .

Under limited commitment, the calibrated money market access probability is $\sigma=0.625$, while with full commitment we obtain $\sigma=0$ (no financial intermediation). This clearly contradicts the facts, since there is a highly developed financial sector in the United Kingdom, and so we disregard the full commitment model. Furthermore, the log-log and the semi-log specification do less well in replicating the empirical money demand function as compared to our model with limited commitment.

A further observation that supports our finding that limited commitment is important in the United Kingdom is the correlation between the ratio of credit to M1 and nominal interest rates, which is 0.93 for the private nonfinancial sector. Our model with limited commitment comes very close to this estimate and produces a value of 0.89 , while we obtain a value of 0 under full commitment since $\sigma=0$.

\footnotetext{
${ }^{26}$ For both the full commitment and limited commitment models, we calculate the welfare cost of inflation as the percentage of total consumption that agents would be willing to give up in order to be in a steady state with a nominal interest rate of 3 percent instead of 13 percent. For the log-log and the semi-log specification, we follow Lucas (2000) and calculate the welfare cost of inflation as the area underneath the money demand function for interest rates between 3 and 13 percent.
} 


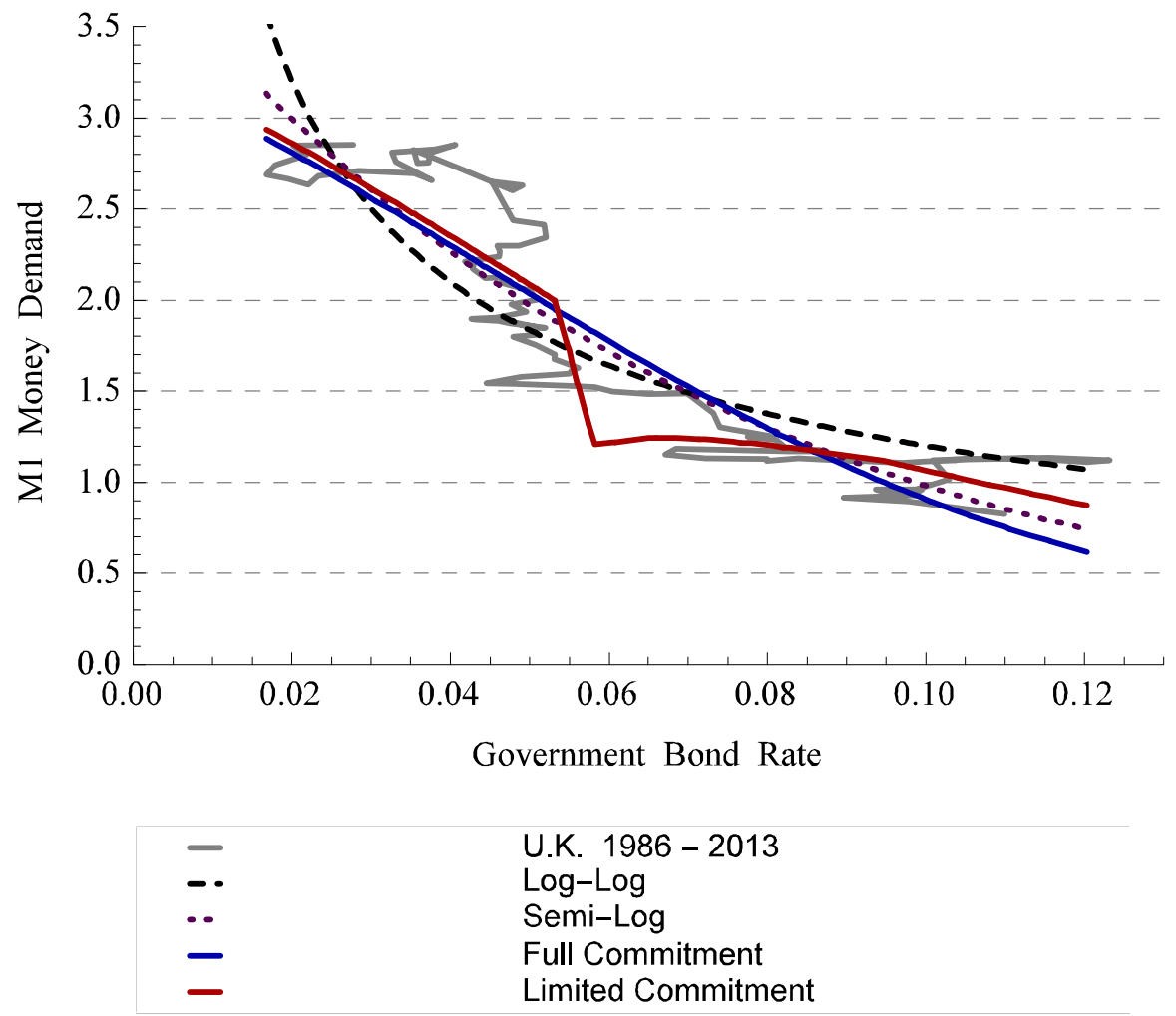

Figure 7: Simulation Results For the U.K.

In Figure 7, we show the money demand curves for the four different specifications mentioned above. It combines Figure 1 and Figure 2, and therefore we do not discuss it here again.

\section{Robustness}

In order to verify that limited commitment also improves the fit of money demand for other countries in addition to that of U.K., we now present our numerical results for Australia, Canada and the United States. For these countries we found a comparable data set for the same sample period. As before, we use quarterly data from 1986 to 2013 and set $i$ equal to the average annual rate on government bonds with a maturity of 10 years, while we choose $\beta=(1+r)^{-1}$ such that the model replicates the real interest rate in the data, measured as the difference between $i$ and the average annual inflation rate. Furthermore, we keep the technology parameter $n=0.5$ in order to maximize the number of matches. Finally, we calibrate the unknown parameters $A, \alpha, \sigma$, and $\theta$, by minimizing the sum of squared differences between the model-implied and the observed money demand, and by matching the goods market mark-up simultaneously. 


\subsection{Australia}

For Australia, we obtain the following targets: $i=0.074$ and $\beta=(1+r)^{-1}=0.962$, where $r=0.040$. Martins et al. (1996) provide an average mark-up of 17 percent for Australia, which we use as a calibration target. Table 3 summarizes the calibration and simulation results.

Table 3: Calibration and simulation results for Australia ${ }^{a}$

\begin{tabular}{llllllllllll}
\hline \hline Method & $A$ & $\alpha$ & $\theta$ & $\sigma$ & $i_{F}$ & $i_{1}$ & $i_{2}$ & $i_{3}$ & $s_{G M}$ & $\Delta$ & $\Sigma$ sq. diff. \\
\hline Log-Log & 0.22 & 0.41 & - & - & - & - & - & - & - & 0.026 & 0.69 \\
Semi-Log & 1.02 & 6.36 & - & - & - & - & - & - & - & 0.030 & 0.43 \\
Full Com. & 0.75 & 0.42 & 0.87 & 0.000 & 0.000 & - & - & - & 0.16 & 0.037 & 0.46 \\
Limited Com. & 1.05 & 0.99 & 1.00 & 0.625 & - & 0.061 & 0.125 & 0.126 & 0.18 & 0.019 & 0.28 \\
\hline
\end{tabular}

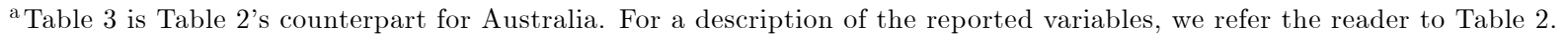

As for the United Kingdom, we find for Australia that our model with limited commitment succeeds best in replicating the data; i.e., we obtain a sum of squared differences between the theoretical money demand and the data of 0.28 as compared to 0.43 for the semi-log specification (second-best fit). Furthermore, Table 3 shows that limited commitment significantly reduces the welfare cost of inflation. We obtain 1.9 percent under limited commitment, whereas the other three methods result in estimates between 2.6 and 3.7 percent. As for the United Kingdom, we find for the calibration under full commitment that $\sigma=0$ results in the best fit between the model and the data. That is, our model with full commitment suggests that Australia does not have any financial intermediation, which strongly contradicts the reality. 


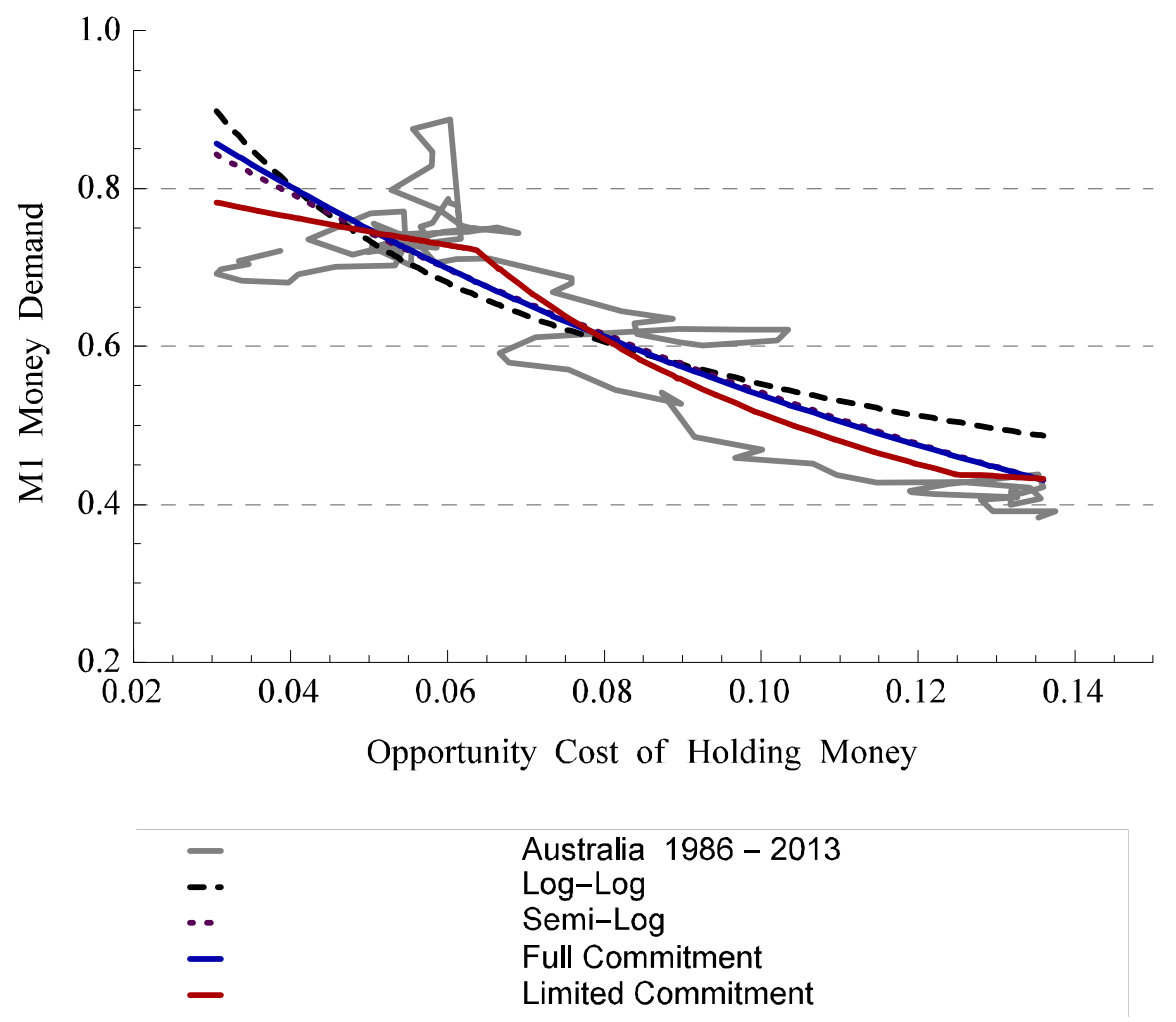

Figure 8: Simulation Results for Australia

Figure 8 shows that limited commitment does a good job in replicating the low elasticity of money demand for low nominal interest rates and the high elasticity for intermediate nominal interest rates, whereas the standard methods fail to replicate this relationship. As for the United Kingdom, we find for Australia a positive relationship between the ratio of credit to M1 and nominal interest rates. Concretely, the correlation between the ratio of credit to M1 and nominal interest rates is 0.35 for the private nonfinancial sector, while our model estimates a value of 0.97 .

\subsection{Canada}

For Canada, we obtain the following targets: $i=0.060$ and $\beta=(1+r)^{-1}=0.965$, where $r=0.036$. Martins et al. (1996) provide an average mark-up of 20 percent for Canada, which we use as a calibration target. Table 4 summarizes the calibration and simulation results. 
Table 4: Calibration and simulation results for Canada ${ }^{\text {a }}$

\begin{tabular}{llllllllllll}
\hline \hline Method & $A$ & $\alpha$ & $\theta$ & $\sigma$ & $i_{F}$ & $i_{1}$ & $i_{2}$ & $i_{3}$ & $s_{G M}$ & $\Delta$ & $\Sigma$ sq. diff. \\
\hline Log-Log & 0.24 & 0.45 & - & - & - & - & - & - & - & 0.036 & 0.45 \\
Semi-Log & 1.54 & 8.95 & - & - & - & - & - & - & - & 0.051 & 0.80 \\
Full Com. & 0.38 & 0.34 & 0.80 & 0.250 & 0.042 & - & - & - & 0.28 & 0.060 & 0.52 \\
Limited Com. & 0.46 & 0.34 & 0.80 & 0.000 & - & - & - & - & 0.22 & 0.064 & 0.81 \\
\hline
\end{tabular}

a Table 4 is Table 2's counterpart for Canada.

The log-log specification replicates the data best, followed by our model with full commitment. Limited commitment does not improve the fit when compared to these methods. Furthermore, for limited commitment the optimal money market access probability is $\sigma=0$. This is odd, since in the Canadian data we observe a positive correlation between the ratio of credit to M1 and nominal interest rates, which equals 0.73 for the private nonfinancial sector. This finding suggests that limited commitment also affects the Canadian economy, but that our calibration is not able to identify it.

When we look at the data, it becomes clear that Canada exhibits a very elastic money demand for very low interest rates (see Figure 9). However, our calibration implies that the type-II equilibrium (where money demand is highly elastic) only prevails for higher nominal interest rates.

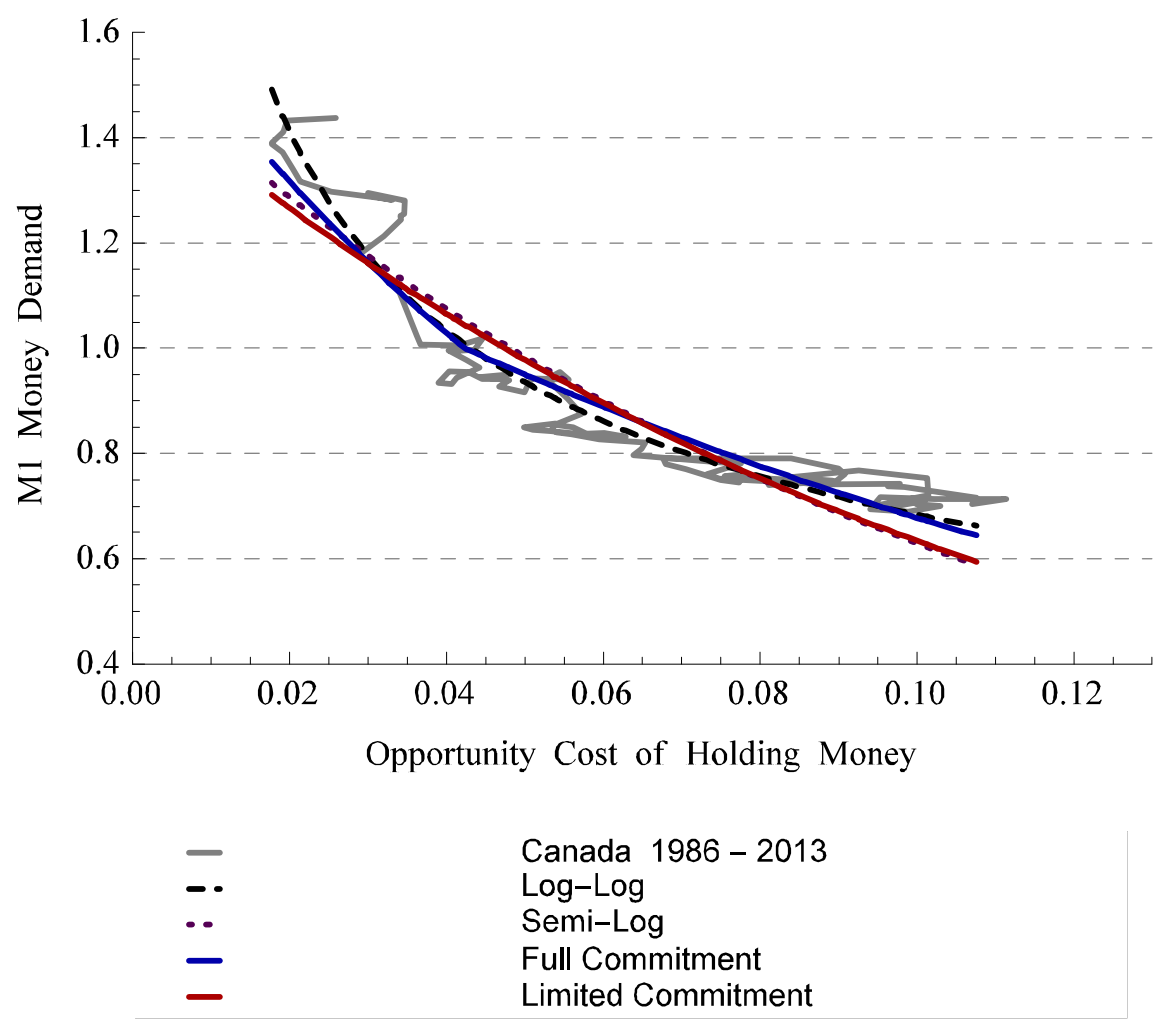

Figure 9: Simulation Results for Canada 
As a robustness check we recalibrate the limited commitment model for lower values of $r$. From the theoretical section, recall that only the borrowing limit depends directly on $r$ :

$$
\phi \bar{\ell}=\frac{(1-n) \delta}{r\left(1+i_{m}\right)} \Omega .
$$

Note that neither the model with full commitment nor the Lucas specifications are affected by a change in $r$, and so we can continue to compare the results for different values of $r$ with those in Table 4. Note also, from (25), that decreasing $r$ affects the borrowing limit in the same way as lowering $n$ or increasing $\delta$ and so instead of using $r$ we could also use these parameter for our robustness check. We present our findings for lower values of $r$ in Table 5 .

Table 5: Calibration Results for Canada For lower values of $r^{\mathrm{a}}$

\begin{tabular}{lllllllllll}
\hline \hline Method & $A$ & $\alpha$ & $\theta$ & $\sigma$ & $i_{1}$ & $i_{2}$ & $i_{3}$ & $s_{G M}$ & $\Delta$ & $\Sigma$ sq. diff. \\
\hline Limited Com. $r=0.0200$ & 0.50 & 0.68 & 0.93 & 0.650 & 0.031 & 0.059 & 0.060 & 0.32 & 0.029 & 0.36 \\
Limited Com. $r=0.0225$ & 0.52 & 0.77 & 0.96 & 0.700 & 0.032 & 0.062 & 0.062 & 0.32 & 0.026 & 0.42 \\
Limited Com. $r=0.0250$ & 0.52 & 0.88 & 0.98 & 0.775 & 0.032 & 0.060 & 0.060 & 0.33 & 0.023 & 0.48 \\
Limited Com. $r=0.0275$ & 0.52 & 0.96 & 0.99 & 0.825 & 0.033 & 0.058 & 0.058 & 0.34 & 0.021 & 0.63 \\
Limited Com. $r=0.0300$ & 0.45 & 0.33 & 0.79 & 0.000 & - & - & - & 0.22 & 0.068 & 0.81 \\
\hline
\end{tabular}

${ }^{a}$ Table 5 shows the calibration results for Canada under limited commitment for different values of the real interest rate $r$.

Table 5 shows that our model replicates the data very well for lower values of $r$. In particular, for $r=0.020$, we find that the model with limited commitment provides a better fit than all other methods. Furthermore, for $r=0.020$ the correlation between the ratio of credit to M1 and nominal interest rates in the model is 0.88 , which comes close to its empirical counterpart of 0.73 . As mentioned above, we could have also decreased $n$ or increased $\delta$ to obtain a better fit for the limited commitment model for Canada.

Beside this, we find that for any real interest rate that results in a strictly positive access probability, the estimated welfare cost of inflation is significantly lower than the values obtained by the traditional methods. For instance, for $r=0.025$ we find an optimal value of the money market access probability of $\sigma=0.825$ and a welfare cost of inflation of $\Delta=0.021$, whereas the three other methods result in estimates of the welfare cost of inflation between 3.6 and 6 percent. For ease of understanding, we show in Figure 10 the resulting money demand curves for different values of $r$. 


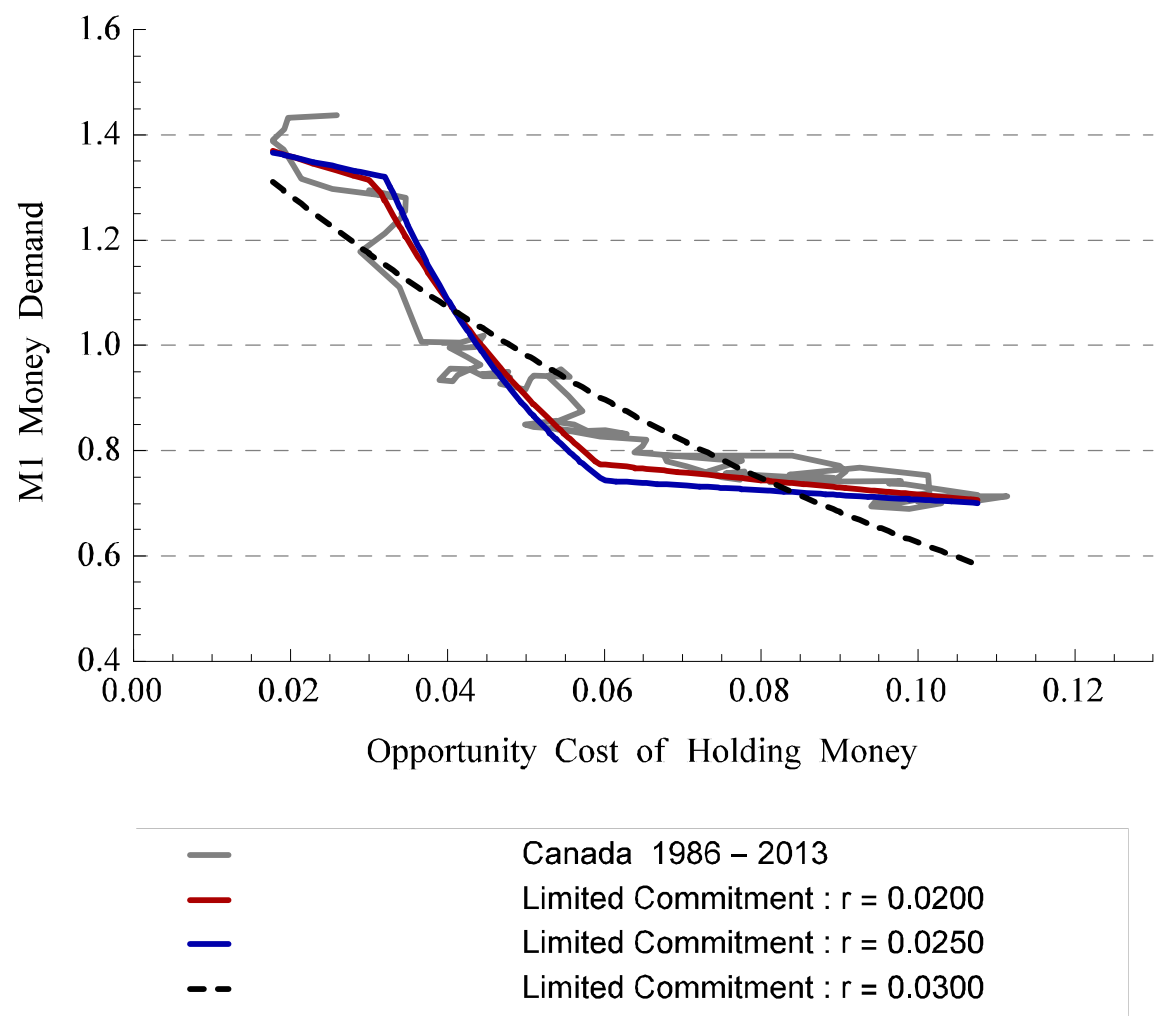

Figure 10: Lower RATe of time PREFERENCE

The above figure shows that for lower values of the real interest rate, the critical value $i_{1}$ moves to the left, which improves the fit with the data. To summarize, we find that our model proves competent in replicating the Canadian data well, if we assume a real interest rate of $0.020 \leq r<0.030$, which results in a highly elastic money demand curve for low nominal interest rates.

\subsection{United States}

For the United States, we obtain the following targets: $i=0.055$ and $\beta=(1+r)^{-1}=0.974$, where $r=0.026$. Martins et al. (1996) provide an average mark-up of 15 percent for the United States, which we use as a calibration target. Table 6 summarizes the calibration and simulation results. 
Table 6: Calibration and simulation Results for the U.S. ${ }^{a}$

\begin{tabular}{llllllllllll}
\hline \hline Method & $A$ & $\alpha$ & $\theta$ & $\sigma$ & $i_{F}$ & $i_{0}$ & $i_{1}$ & $i_{2}$ & $s_{G M}$ & $\Delta$ & $\Sigma$ sq. diff. \\
\hline Log-Log & 0.09 & 0.20 & - & - & - & - & - & - & - & 0.003 & 0.0067 \\
Semi-Log & 0.19 & 3.85 & - & - & - & - & - & - & - & 0.004 & 0.0097 \\
Full Com. & 5.32 & 0.99 & 1.00 & 0.375 & 0.196 & - & - & - & 0.04 & 0.004 & 0.0089 \\
Limited Com. & 5.40 & 0.75 & 0.96 & 0.000 & - & - & - & - & 0.04 & 0.004 & 0.0092 \\
\hline
\end{tabular}

a Table 6 is Table 2's counterpart for the United States.

For the United States, limited commitment does not improve the fit between the theoretical money demand function and its empirical counterpart and the log-log specification succeeds best in replicating the data (see Table 6 and Figure 11). Table 6 also shows that all methods imply a low welfare cost of inflation, ranging from 0.3 and 0.4 percent. Furthermore, we obtain a positive money market access probability under full commitment which equals $\sigma=0.375$, whereas limited commitment results in $\sigma=0$.

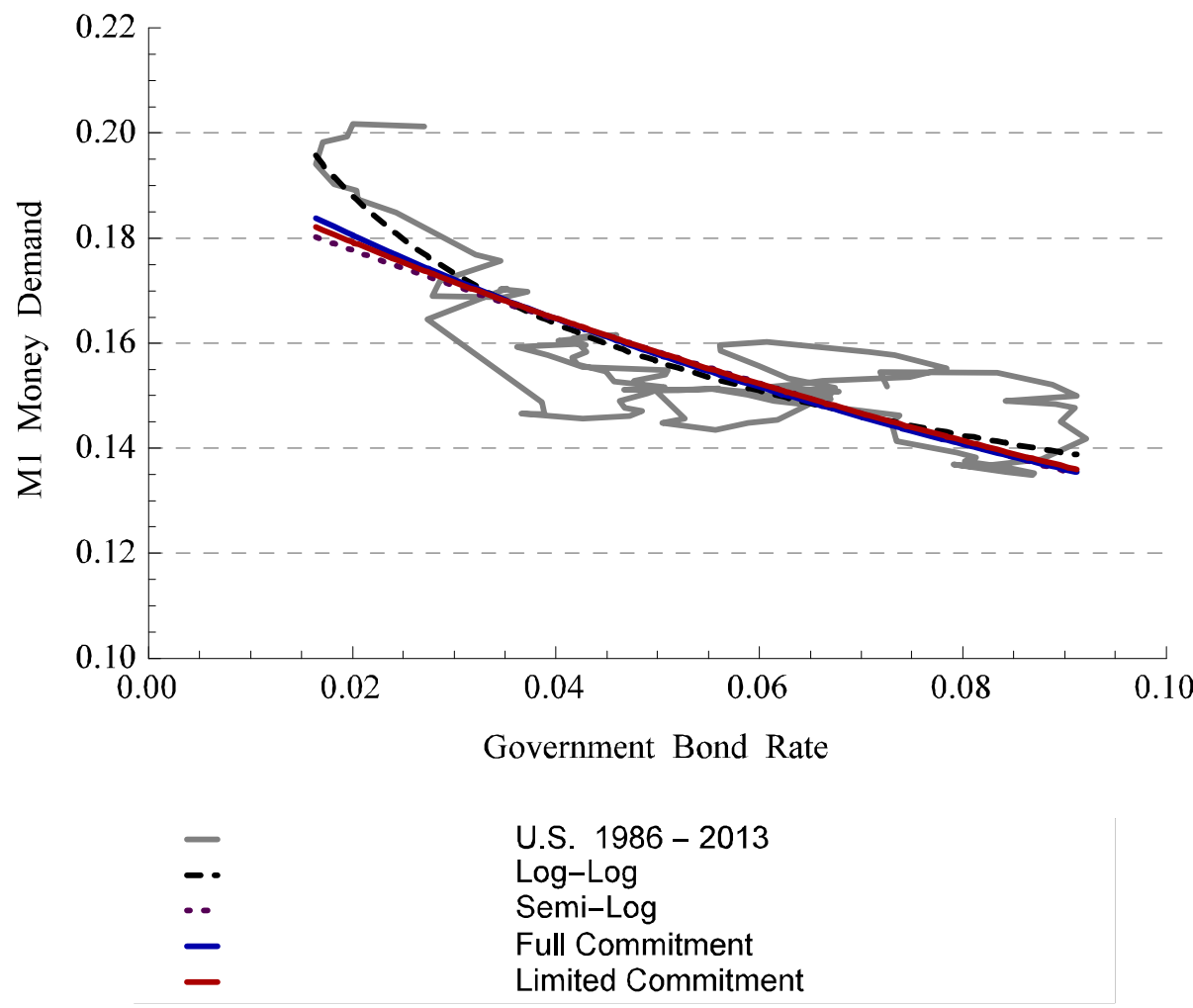

Figure 11: Simulation Results For the U.S.

This calibration result does not imply that limited commitment is unimportant for the United States. It only means that our model is not able to identify it. One reason could be that for the U.S. we do 
not capture the legal system as represented by our punishment scheme very well. For example, in the theory section, we showed that the allocation under limited commitment gets close to the one under full commitment if we assume a more severe punishment scheme. Another reason is that financial regulations and financial innovations also affect the money demand function (see the discussion in the literature section) and that these innovations are more important to explain U.S. money demand (see Berentsen et al. 2015).

\section{Conclusion}

Using a "New Monetarist" approach, we build a model that incorporates a money market where agents can borrow and deposit money. We first show in theory how limited commitment affects the relationship between money demand and nominal interest rates. We then calibrate the model and demonstrate that limited commitment significantly improves the fit between the theoretical money demand function and the historical money demand data for the United Kingdom, Australia, and Canada in the post-1985 period. Our model also implies that there is a positive correlation between nominal interest rates and credit activity, a finding that is consistent with the data of the three analyzed countries. Standard models, which assume full commitment of borrowers via banks, have a hard time in replicating this fact. 


\section{Appendix I: Proofs}

Proof of Lemma 1. Since a buyer has to work to repay his debt, he may decide to default in the centralized market. Here, we derive conditions such that debt repayment is voluntary. A defaulting buyer's value function at the beginning of the centralized market is

$$
\tilde{V}_{3}(m)=U\left(x^{*}\right)-\tilde{h}+\beta \tilde{V}_{+1}\left(\tilde{m}_{+1}\right),
$$

and his budget constraint is $x^{*}+\phi \tilde{m}_{+1}=\tilde{h}+\phi m+\phi T$. Note that nonrepayment only affects hours of work and the amount of money a buyer takes into the next period. By eliminating $\tilde{h}$ using the budget constraint, the value function $\tilde{V}_{3}(m)$ can be rewritten as

$$
\tilde{V}_{3}(m)=U\left(x^{*}\right)-x^{*}-\phi \tilde{m}_{+1}+\phi m+\phi T+\beta \tilde{V}_{+1}\left(\tilde{m}_{+1}\right) .
$$

The value function of a buyer who repays his loan in the centralized market is

$$
V_{3}(m)=U\left(x^{*}\right)-h+\beta V_{+1}\left(m_{+1}\right),
$$

and his budget constraint is $x^{*}+\phi m_{+1}=h+\phi m+\phi T-\phi(1+i) \ell$. By eliminating $h$ using the budget constraint, we can rewrite $V_{3}(m)$ as

$$
V_{3}(m)=U\left(x^{*}\right)-x^{*}-\phi m_{+1}+\phi m+\phi T-\phi\left(1+i_{m}\right) \ell+\beta V_{+1}\left(m_{+1}\right) .
$$

A buyer repays his loan if, and only if, $V_{3}(m) \geq \tilde{V}_{3}(m)$, which implies

$$
\phi\left(1+i_{m}\right) \ell \leq \phi \tilde{m}_{+1}-\phi m_{+1}+\beta\left[V_{+1}\left(m_{+1}\right)-\tilde{V}_{+1}\left(\tilde{m}_{+1}\right)\right] .
$$

Let us now derive $\tilde{V}_{+1}\left(\tilde{m}_{+1}\right)$ and $V_{+1}\left(m_{+1}\right)$.

Derivation of $\tilde{V}_{+1}\left(\tilde{m}_{+1}\right)$. A deviator is banned forever from the money market. The next-period value function of a deviator is

$$
\tilde{V}_{+1}\left(\tilde{m}_{+1}\right)=\frac{1}{1-\beta}\left[(1-n) \delta u(\tilde{q})-n \delta^{s} \bar{q}+U\left(x^{*}\right)-\tilde{h}\right],
$$

where $\bar{q} \equiv \pi \hat{q}+(1-\sigma) q$ is the expected (or average) quantity he produces if he is a seller; with probability $\sigma$ the buyer he meets is active, in which case he produces $\hat{q}$, while with probability $1-\sigma$ the buyer is passive, in which case he produces $q$. The first two terms within brackets are the expected net payoff in the goods market, while the third and fourth terms equal the net payoff in the centralized market. Expected hours of work for a deviator in the centralized market are $\tilde{h}=(1-n) \tilde{h}_{b}+n \tilde{h}_{s}$, where $\tilde{h}_{b}$ and $\tilde{h}_{s}$ are expected hours of work of a buyer and a seller, respectively, and are defined as

$$
\begin{aligned}
\tilde{h}_{b}= & \delta\left[x^{*}+\phi_{+1} \tilde{m}_{+2}-\phi_{+1} \tilde{m}_{+1}-\phi_{+1} T_{+1}+g(\tilde{q})\right] \\
& +(1-\delta)\left[x^{*}+\phi_{+1} \tilde{m}_{+2}-\phi_{+1} \tilde{m}_{+1}-\phi_{+1} T_{+1}\right] \\
= & x^{*}+\phi_{+1} \tilde{m}_{+2}-\phi_{+1} \tilde{m}_{+1}-\phi_{+1} T_{+1}+\delta g(\tilde{q})
\end{aligned}
$$


and

$$
\begin{aligned}
\tilde{h}_{s}= & \delta^{s}\left[x^{*}+\phi_{+1} \tilde{m}_{+2}-\phi_{+1} \tilde{m}_{+1}-\phi_{+1} T_{+1}-\bar{g}\right] \\
& +\left(1-\delta^{s}\right)\left[x^{*}+\phi_{+1} \tilde{m}_{+2}-\phi_{+1} \tilde{m}_{+1}-\phi_{+1} T_{+1}\right] \\
= & x^{*}+\phi_{+1} \tilde{m}_{+2}-\phi_{+1} \tilde{m}_{+1}-\phi_{+1} T_{+1}-\delta^{s} \bar{g}
\end{aligned}
$$

respectively. If the deviator is a seller in the next period, then he receives an average amount of money, in real terms, equal to $\bar{g} \equiv \sigma g(\hat{q})+(1-\sigma) g(q)$ in the goods market. Hence, using $(1-n) \delta^{s}=n \delta$, expected hours of work for a deviator can be rewritten as

$$
\begin{aligned}
\tilde{h} & =(1-n) \tilde{h}_{b}+n \tilde{h}_{s} \\
& =x^{*}+\phi_{+1} \tilde{m}_{+2}-\phi_{+1} \tilde{m}_{+1}-\phi_{+1} T_{+1}+(1-n) \delta[g(\tilde{q})-\bar{g}] .
\end{aligned}
$$

Moreover, using $\tilde{m}_{+2}=\gamma \tilde{m}_{+1}$ and $T_{+1}=(\gamma-1) m_{+1}$, we can rewrite $\tilde{h}$ as follows

$$
\begin{aligned}
\tilde{h} & =x^{*}+(\gamma-1) \phi_{+1} \tilde{m}_{+1}-(\gamma-1) \phi_{+1} m_{+1}+(1-n) \delta[g(\tilde{q})-\bar{g}] \\
& =x^{*}+(\gamma-1)[g(\tilde{q})-g(q)]+(1-n) \delta[g(\tilde{q})-\bar{g}] .
\end{aligned}
$$

Substituting $\tilde{h}$ into $\tilde{V}_{+1}\left(\tilde{m}_{+1}\right)$ yields

$$
\tilde{V}_{+1}\left(\tilde{m}_{+1}\right)=\frac{1}{1-\beta}\left\{\begin{array}{c}
(1-n) \delta u(\tilde{q})-n \delta^{s} \bar{q}+U\left(x^{*}\right)-x^{*} \\
-(\gamma-1)[g(\tilde{q})-g(q)]-(1-n) \delta[g(\tilde{q})-\bar{g}]
\end{array}\right\} .
$$

Derivation of $V_{+1}\left(m_{+1}\right)$. Let $\bar{u} \equiv \sigma u(\hat{q})+(1-\sigma) u(q)$ be the expected utility of a nondefaulting buyer in the goods market. If the buyer is active, he enjoys utility $u(\hat{q})$; if he is passive, he enjoys utility $u(q)$. The next-period value function of a nondefaulter is

$$
V_{+1}\left(m_{+1}\right)=\frac{1}{1-\beta}\left\{(1-n) \delta \bar{u}-n \delta^{s} \bar{q}+U\left(x^{*}\right)-h\right\} .
$$

Note that the average disutility, $\bar{q}$, suffered by a seller in the goods market depends on his trading partner's participation status, active vs passive, and not on his participation status. Expected hours of work of a nondefaulter in the centralized market are $h=(1-n) h_{b}+n h_{s}$, where

$$
\begin{aligned}
h_{b}= & \delta\left[x^{*}+\phi_{+1} m_{+2}-\phi_{+1} m_{+1}-\phi_{+1} T_{+1}+\bar{g}\right] \\
& +(1-\delta)\left[x^{*}+\phi_{+1} m_{+2}-\phi_{+1} m_{+1}-\phi_{+1} T_{+1}\right] \\
= & x^{*}+\phi_{+1} m_{+2}-\phi_{+1} m_{+1}-\phi_{+1} T_{+1}+\delta \bar{g}
\end{aligned}
$$

and

$$
\begin{aligned}
h_{s}= & \delta^{s}\left[x^{*}+\phi_{+1} m_{+2}-\phi_{+1} m_{+1}-\phi_{+1} T_{+1}-\bar{g}\right] \\
& +\left(1-\delta^{s}\right)\left[x^{*}+\phi_{+1} m_{+2}-\phi_{+1} m_{+1}-\phi_{+1} T_{+1}\right] \\
= & x^{*}+\phi_{+1} m_{+2}-\phi_{+1} m_{+1}-\phi_{+1} T_{+1}-\delta^{s} \bar{g} .
\end{aligned}
$$


Hence, average hours of work for a nondefaulter are

$$
\begin{aligned}
h & =(1-n) h_{b}+n h_{s} \\
& =x^{*}+\phi_{+1} m_{+2}-\phi_{+1} m_{+1}-\phi_{+1} T_{+1} \\
& =x^{*}
\end{aligned}
$$

where we have used $T_{+1}=m_{+2}-m_{+1}$. By replacing $h$ in $V_{+1}\left(m_{+1}\right)$, we obtain

$$
V_{+1}\left(m_{+1}\right)=\frac{1}{1-\beta}\left\{(1-n) \delta \bar{u}-n \delta^{s} \bar{q}+U\left(x^{*}\right)-x^{*}\right\} .
$$

Using the above expressions to eliminate $V_{+1}\left(m_{+1}\right)$ and $\tilde{V}_{+1}\left(\tilde{m}_{+1}\right)$ in $(26)$, we obtain

$$
\begin{aligned}
\phi\left(1+i_{m}\right) \ell \leq & \phi \tilde{m}_{+1}-\phi m_{+1}+\beta\left[V_{+1}\left(m_{+1}\right)-\tilde{V}_{+1}\left(\tilde{m}_{+1}\right)\right] \\
= & \gamma[\phi \tilde{m}-\phi m]+\frac{\beta}{1-\beta}\left\{\begin{array}{c}
(1-n) \delta[\sigma u(\hat{q})+(1-\sigma) u(q)] \\
-n \delta^{s} \bar{q}+U\left(x^{*}\right)-x^{*}
\end{array}\right\} \\
& +\frac{\beta}{1-\beta}\left[\begin{array}{c}
-(1-n) \delta u(\tilde{q})+n \delta^{s} \bar{q}-U\left(x^{*}\right)+x^{*} \\
+(\gamma-1)[g(\tilde{q})-g(q)]+(1-n) \delta[g(\tilde{q})-\bar{g}]
\end{array}\right]
\end{aligned}
$$

or, after further simplification,

$$
\begin{aligned}
\phi \ell \leq & \frac{i[g(\tilde{q})-g(q)]}{r\left(1+i_{m}\right)} \\
& +\frac{(1-n) \delta\{\sigma[u(\hat{q})-g(\hat{q})]+(1-\sigma)[u(q)-g(q)]-[u(\tilde{q})-g(\tilde{q})]\}}{r\left(1+i_{m}\right)}
\end{aligned}
$$

where $\tilde{q}$ satisfies $(7), r=(1-\beta) \beta^{-1}$, and $i=(\gamma-\beta) \beta^{-1}$.

Derivation of (7). The envelope condition for a deviator in the money market is

$$
\frac{\partial \tilde{V}_{1}}{\partial m}=(1-n) \frac{\partial \tilde{V}_{2}^{b}}{\partial m}+n \frac{\partial \tilde{V}_{2}^{s}}{\partial m}
$$

which, substituting $\partial \tilde{V}_{2}^{b} / \partial m$ and $\partial \tilde{V}_{2}^{s} / \partial m$, can be written as

$$
\frac{\partial \tilde{V}_{1}}{\partial m}=(1-n) \phi\left[\delta \frac{u^{\prime}(\tilde{q})}{g^{\prime}(\tilde{q})}+1-\delta\right]+n \phi .
$$

Updating the previous equation one period ahead, and using the first-order condition in the centralized market, we obtain (7).

Derivation of (10). To derive the marginal value of money, we first need to characterize the solutions to the agent's decision problems. The first-order conditions of the agent's problem in the centralized market (1) are

$$
U^{\prime}(x)=1, \quad \text { and } \quad \frac{\beta \partial V_{1}}{\partial m_{+1}}=\phi .
$$


The term $\beta \partial V_{1} / \partial m_{+1}$ reflects the marginal value of taking one additional unit of money into the next period, and $\phi$ is the marginal cost of doing so. As in Lagos and Wright (2005), the choice of $m_{+1}$ is independent of $m$. As a result, each agent exits the centralized market with the same amount of money. The envelope conditions are

$$
\frac{\partial V_{3}}{\partial m}=\phi, \quad \frac{\partial V_{3}}{\partial d}=\phi\left(1+i_{m}\right), \quad \text { and } \quad \frac{\partial V_{3}}{\partial \ell}=-\phi\left(1+i_{m}\right) .
$$

The marginal value of money at the beginning of the centralized market is equal to the price of money in terms of general goods. This implies that the value function $V_{3}$ is linear in $m$.

In the goods market, the envelope conditions of a buyer are

$$
\frac{\partial V_{2}^{b}}{\partial m}=\delta\left[u^{\prime}(q) \frac{\partial q}{\partial m}+\phi\left(1-\frac{\partial z}{\partial m}\right)\right]+(1-\delta) \phi, \quad \text { and } \quad \frac{\partial V_{2}^{b}}{\partial \ell}=-\phi\left(1+i_{m}\right) .
$$

If the buyer's cash constraint is not binding, then $\frac{\partial q}{\partial m}=0$ and $\frac{\partial z}{\partial m}=0$. In this case, the buyer's first envelope condition reduces to $\frac{\partial V_{2}^{b}}{\partial m}=\frac{\partial V_{3}}{\partial m}=\phi$. If the constraint is binding, then $\frac{\partial q}{\partial m}=\frac{\phi}{g^{\prime}(q)}$ and $\frac{\partial z}{\partial m}=1$. In this case, the buyer's envelope conditions in the goods market become

$$
\frac{\partial V_{2}^{b}}{\partial m}=\delta \phi \frac{u^{\prime}(q)}{g^{\prime}(q)}+\phi(1-\delta), \quad \text { and } \quad \frac{\partial V_{2}^{b}}{\partial \ell}=-\phi\left(1+i_{m}\right) .
$$

In the goods market, the envelope conditions of a seller are

$$
\frac{\partial V_{2}^{s}}{\partial m}=\phi, \quad \text { and } \quad \frac{\partial V_{2}^{s}}{\partial d}=\phi\left(1+i_{m}\right)
$$

In the money market, the first-order condition of the buyer's problem (8) is

$$
\frac{\partial V_{2}^{b}}{\partial m}+\frac{\partial V_{2}^{b}}{\partial \ell}=\lambda_{\Phi}
$$

where $\lambda_{\Phi}$ denotes the Lagrange multiplier on the buyer's borrowing constraint (5). The first-order condition of the seller's problem (9) in the money market is

$$
-\frac{\partial V_{2}^{s}}{\partial m}+\frac{\partial V_{2}^{s}}{\partial d}=\lambda_{s}
$$

The envelope condition of (4) is

$$
\frac{\partial V_{1}}{\partial m}=\sigma\left[(1-n) \frac{\partial V_{1}^{b}}{\partial m}+n \frac{\partial V_{1}^{s}}{\partial m}\right]+(1-\sigma)\left[(1-n) \frac{\partial V_{2}^{b}}{\partial m}+n \frac{\partial V_{2}^{s}}{\partial m}\right] .
$$

Applying the envelope theorem to (8) and (9), the above envelope condition can be rewritten as

$$
\frac{\partial V_{1}}{\partial m}=\sigma\left[(1-n) \frac{\partial V_{2}^{b}}{\partial m}+n\left(\frac{\partial V_{2}^{s}}{\partial m}+\lambda_{s}\right)\right]+(1-\sigma)\left[(1-n) \frac{V_{2}^{b}}{\partial m}+n \frac{V_{2}^{s}}{\partial m}\right]
$$


Eliminating $\frac{\partial V_{2}^{b}}{\partial m}, \lambda_{s}$, and $\frac{V_{2}^{s}}{\partial m}$ in (33) using (29), (32), and (30), respectively, we get the following expression

$$
\frac{\partial V_{1}}{\partial m}=\sigma \phi\left\{(1-n) \delta\left[\frac{u^{\prime}(\hat{q})}{g^{\prime}(\hat{q})}-1\right]+n i_{m}\right\}+\phi(1-\sigma)(1-n) \delta\left[\frac{u^{\prime}(q)}{g^{\prime}(q)}-1\right]+\phi
$$

Updating this expression by one period, and using (27) to replace $\frac{\partial V_{1}}{\partial m_{+1}}$, we get (10).

Proof of Proposition 1. Equations (6), (7), (10), and (11)-(13) hold in a type-0 equilibrium.

Derivation of (6) and (7). In the Proof of Lemma 1.

Derivation of (10). Immediately after the Proof of Lemma 1.

Derivation of (11). Equation (11) means that the real amount of money an active buyer spends in the goods market, $g(\hat{q})$, is equal to the real amount of money spent as a passive buyer, $g(q)$, plus the real loan an active buyer receives from the bank, $\phi \ell$. To see this, first note that both active buyers and passive buyers enter the money market with the same amount of money, $m$. However, only active buyers can borrow $\ell$ units of money. Consequently, passive buyers can spend $m$ units of money in the goods market, while active buyers can spend $\hat{m}=m+\ell$ units of money. But these are all nominal amounts. To get real quantities, multiply everything by $\phi$, and obtain $g(\hat{q})=\phi \hat{m}$ and $g(q)=\phi m$, where we have used (3). Then, substituting terms yields $g(\hat{q})=g(q)+\phi \ell$.

Derivation of (12). In a type-0 equilibrium, a buyer's borrowing constraint is not binding (i.e., $\left.\lambda_{\Phi}=0\right)$. Substituting $\lambda_{\Phi}=0$ in $(31)$, we obtain $\frac{\partial V_{2}^{b}}{\partial m}+\frac{\partial V_{2}^{b}}{\partial \ell}=0$. Use (29) to eliminate $\frac{\partial V_{2}^{b}}{\partial m}$ and $\frac{\partial V_{2}^{b}}{\partial \ell}$ in the last equation to get (12).

Derivation of (13). In a type-0 equilibrium, a seller's cash constraint is not binding (i.e., $\lambda_{s}=0$ ). Using $\lambda_{s}=0$ in (32), we obtain $\frac{\partial V_{2}^{s}}{\partial m}=\frac{\partial V_{2}^{s}}{\partial d}$. Next, use (30) to substitute $\frac{\partial V_{2}^{s}}{\partial m}$ and $\frac{\partial V_{2}^{s}}{\partial d}$ into the last equation to get (13).

Proof of Proposition 2. Equations (6), (7), (10), and (14)-(16) hold in a type-I or a type-II equilibrium. All these equations, except (15), are the same as their counterparts in Proposition 1 and we refer to the Proof of Proposition 1 for their derivation.

Derivation of (15). This derivation is straightforward. To see this, note that the (real) amount of loans a buyer borrows from the bank is equal to the maximum (real) amount of loans he can get. This is a direct consequence of the fact that his borrowing constraint is binding in a type-I or a type-II equilibrium.

Proof of Proposition 3. Equations (6), (7), (10), and (17)-(19) hold in a type-III equilibrium. All the equilibrium equations in Proposition 3, except (19), are the same as their counterparts in Proposition 2. We refer to the Proof of Proposition 2 for their derivation.

Derivation of (19). In a type-III equilibrium, active sellers deposit all their money at the bank; i.e., $d=m$. Moreover, active buyers carry $\hat{m}$ units of money out of the money market, where $\hat{m}=m+\ell$, and the market clearing condition in the money market requires that total deposits must be equal to total loans; i.e., $\sigma n d=\sigma(1-n) \ell$. Using $d=m$ and $\hat{m}=m+\ell$, the market clearing condition in the money market can be rewritten as $m=(1-n) \hat{m}$. Multiplying each side of the last equation by $\phi$, and using (3), we obtain (19).

Proof of Proposition 4. Equations (6), (7), (10), and (20)-(22) hold in a type-IV equilibrium. All these equations, except (21), are the same as their counterparts in Proposition 3. Equation (21) 
is the same as (12) and comes from the fact that an active buyer is not borrowing-constrained in a type-IV equilibrium. We refer to the Proof of Proposition 1 for its derivation.

Proof of Lemma 2. Let us derive conditions such that debt repayment is voluntary under autarky. To do this, we have to compare the value functions of a defaulter and nondefaulter in the centralized market. The value function of a defaulter in autarky is

$$
\tilde{V}_{3}(m)=U\left(x^{*}\right)-\tilde{h}+\beta \tilde{V}_{+1}(0),
$$

which, using $x^{*}=\tilde{h}+\phi m+\phi T$, can be rewritten as

$$
\tilde{V}_{3}(m)=U\left(x^{*}\right)-x^{*}+\phi m+\phi T+\beta \tilde{V}_{+1}(0) .
$$

A buyer who decides to default knows that he will not have access to the goods market forever and thus he will not carry any money into the next period (i.e., $\tilde{m}_{+1}=0$ ). More precisely, he will not carry any money out of the centralized market never again (i.e., $\tilde{m}_{+1}=\tilde{m}_{+2}=\ldots=\tilde{m}_{+\infty}=0$ ). Note that money is costly to hold and that it is needed for consumption in the goods market. An agent who will not be able to consume in the goods market, such as a defaulter, has no incentive to carry any money out of the centralized market. The value function of a buyer who repays his loan in the centralized market is the same as that in the benchmark case, and we rewrite it below for convenience,

$$
V_{3}(m)=U\left(x^{*}\right)-h+\beta V_{+1}\left(m_{+1}\right),
$$

while his budget constraint is $x^{*}+\phi m_{+1}=h+\phi m+\phi T-\phi(1+i) \ell$. Eliminate $h$ using the budget constraint to obtain

$$
V_{3}(m)=U\left(x^{*}\right)-x^{*}-\phi m_{+1}+\phi m+\phi T-\phi\left(1+i_{m}\right) \ell+\beta V_{+1}\left(m_{+1}\right) .
$$

A buyer pays back his loan if, and only if, $\tilde{V}_{3}(m) \leq V_{3}(m)$ or, equivalently,

$$
\phi\left(1+i_{m}\right) \ell \leq-\phi m_{+1}+\beta\left[V_{+1}\left(m_{+1}\right)-\tilde{V}_{+1}(0)\right] .
$$

The derivation of the value function of a nondefaulter at the beginning of the next period, $V_{+1}\left(m_{+1}\right)$, is the same as that in the benchmark case, and we refer to the Proof of Lemma 1 for its derivation. We rewrite this value function below for convenience,

$$
V_{+1}\left(m_{+1}\right)=\frac{1}{1-\beta}\left[(1-n) \delta \bar{u}-n \delta^{s} \bar{q}+U\left(x^{*}\right)-x^{*}\right] .
$$

The value function of a defaulter at the beginning of the next period, $\tilde{V}_{+1}(0)$, is now

$$
\tilde{V}_{+1}(0)=\frac{1}{1-\beta}\left[U\left(x^{*}\right)-\tilde{h}\right],
$$

where the terms within brackets denote the agent's net payoff in the centralized market. Expected hours of work for a defaulter in the centralized market are $\tilde{h}=(1-n) \tilde{h}_{b}+n \tilde{h}_{s}$, where now we have

$$
\begin{aligned}
\tilde{h}_{b} & =\delta\left[x^{*}-\phi_{+1} T_{+1}\right]+(1-\delta)\left[x^{*}-\phi_{+1} T_{+1}\right] \\
& =x^{*}-\phi_{+1} T_{+1}
\end{aligned}
$$


for a buyer, and

$$
\begin{aligned}
\tilde{h}_{s} & =\delta^{s}\left[x^{*}-\phi_{+1} T_{+1}\right]+\left(1-\delta^{s}\right)\left[x^{*}-\phi_{+1} T_{+1}\right] \\
& =x^{*}-\phi_{+1} T_{+1}
\end{aligned}
$$

for a seller. Note that, in autarky, a defaulter's hours of work are not affected by the preference shock (consume or produce), since a defaulter has no access to the goods market. Consequently, he will enter the centralized market with zero units of money. Substituting terms, we can rewrite the defaulter's value function at the beginning of the next period as

$$
\tilde{V}_{+1}(0)=\frac{1}{1-\beta}\left[U\left(x^{*}\right)-x^{*}+(\gamma-1) \phi m\right],
$$

where we have used $T_{+1}=m_{+2}-m_{+1}=(\gamma-1) m_{+1}$ and $\phi_{+1} m_{+1}=\phi m$. Replacing $\tilde{V}_{+1}(0)$ and $V_{+1}\left(m_{+1}\right)$ into (35), a buyer decides to pay back his debt, if and only if

$$
\begin{aligned}
\phi\left(1+i_{m}\right) \ell & \leq-\phi m_{+1}+\frac{\beta}{1-\beta}\left[\begin{array}{c}
(1-n) \delta \bar{u}-n \delta^{s} \bar{q}+U\left(x^{*}\right)-x^{*} \\
-U\left(x^{*}\right)+x^{*}-(\gamma-1) \phi m
\end{array}\right] \\
& =-\phi m_{+1}+\frac{\beta}{1-\beta}\left[(1-n) \delta \bar{u}-n \delta^{s} \bar{q}-(\gamma-1) \phi m\right]
\end{aligned}
$$

or, equivalently,

$$
\phi \ell \leq-\frac{i}{r\left(1+i_{m}\right)} g(q)+\frac{(1-n) \delta}{r\left(1+i_{m}\right)}\{\sigma[u(\hat{q})-\hat{q}]+(1-\sigma)[u(q)-q]\}
$$

where we have used $m_{+1}=\gamma m, \delta^{s}=(1-n) / n, \phi m=g(q), r=(1-\beta) \beta^{-1}, i=(\gamma-\beta) \beta^{-1}$, and rearranged terms.

\section{Appendix II: Autarky punishment implementation}

To see how the autarky punishment can be implemented, assume two separate locations, island 1 and island 2. The money market takes place on island 1 , while the goods market and the centralized market take place on island 2 (see Figure A.1). Let us assume banks have the exclusive technology to transfer agents between the two islands, costlessly. At the beginning of each period all the agents are transferred to island 1. Then the money market opens and banks trade with active agents who did not default in the past, but do not trade with defaulters or passive agents. Immediately after the money market closes, the agents' identity is checked and nondefaulters, but not defaulters, are transferred to island 2. Defaulters will be transferred to island 2 only at the beginning of the centralized market. It turns out that defaulters will never get a chance to trade again in either the money market or the goods market. They will never trade in the money market again, because, as we have assumed so far, trade is voluntary and banks can (will) always refuse to trade with them. They will never trade in the goods market again, because a bank can (will) always refuse to transfer them to island 2 until the centralized market opens. Consequently, defaulters can only participate in the centralized market. ${ }^{27}$

\footnotetext{
${ }^{27}$ Note that we are still assuming agents' actions are voluntary in this setup. Indeed, buyers know they will be excluded from the goods market if they do not pay back their debt, and the decision to repay the debt is voluntary.
} 


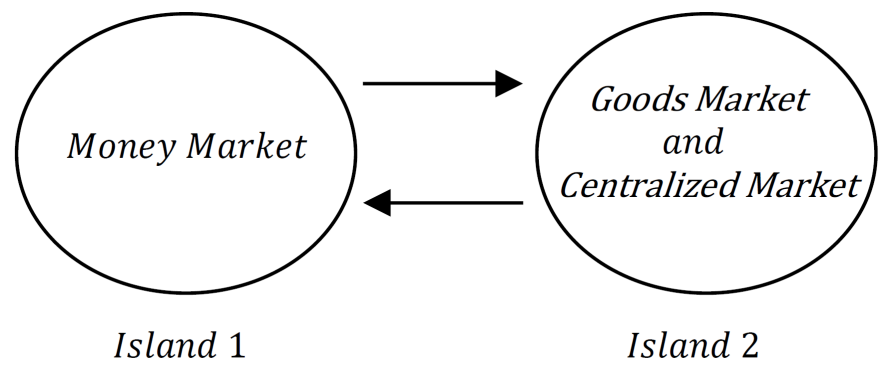

Figure A.1: Setup for autarky

\section{Appendix III: Data sources}

The data we used for the calibration is downloadable from the Federal Reserve Bank of St. Louis FRED database. For all time series, we use quarterly data for the period 1986:Q4 to 2013:Q4. Table A.1. gives a brief overview of the data sources.

TABle A.1: Data source

\begin{tabular}{lll}
\hline \hline Description & Country & Identifier \\
\hline Consumer price index & U.K. & GBRCPIALLQINMEI \\
M1 & U.K. & MANMM101GBM189S \\
Gross domestic product & U.K. & UKNGDP \\
Long-term government bond yield & U.K. & IRLTLT01GBQ156N \\
Total Credit to Private nonfinancial Sector & U.K. & CRDQGBAPABIS \\
Consumer price index & Canada & CANCPIALLQINMEI \\
M1 & Canada & MANMM101CAQ189S \\
Gross domestic product & Canada & CANGDPNQDSMEI \\
Long-term government bond yield & Canada & IRLTLT01CAQ156N \\
Total Credit to Private Non-financial Sector & Canada & CRDQCAAPABIS \\
Consumer price index & Australia & AUSCPIALLQINMEI \\
M1 & Australia & MANMM101AUQ189S \\
Gross domestic product & Australia & AUSGDPNQDSMEI \\
Long-term government bond yield & Australia & IRLTLT01AUQ156N \\
Total Credit to Private Non-financial Sector & Australia & CRDQAUAPABIS \\
M1 adjusted for retail sweeps & U.S. & M1ADJ \\
Gross domestic product & U.S. & GDP \\
Long-term government bond yield & U.S. & IRLTLT01USQ156N \\
Total Credit to Private Non-financial Sector & U.S. & CRDQUSAPABIS \\
\hline
\end{tabular}




\section{References}

[1] Aruoba, S. B., Rocheteau, G., and Waller, C., 2007. "Bargaining and the Value of Money," Journal of Monetary Economics, 54, 2636-2655.

[2] Aruoba, S. B., Waller, C., and Wright, R., 2011. "Money and Capital," Journal of Monetary Economics, 58, 98-116.

[3] Bailey, M., 1956. "The Welfare Cost of Inflationary Finance," Journal of Political Economy, 64, 93-110.

[4] Baumol, W. J., 1952. "The Transactions Demand for Cash: An Inventory Theoretic Approach," Quarterly Journal of Economics, 66, 545-556.

[5] Berentsen, A., Camera, G., and Waller, C., 2007. "Money, Credit and Banking," Journal of Economic Theory, 135, 171-195.

[6] Berentsen, A., Huber, S., and Marchesiani, A., 2015. "Financial Innovations, Money Demand, and the Welfare Cost of Inflation," Journal of Money, Credit, and Banking, 47, 223-261.

[7] Berentsen, A., Menzio, G., and Wright, R., 2011. "Inflation and Unemployment in the Long Run," American Economic Review, 101, 371-98.

[8] Brown, A. J., 1939, "Interest, Prices and the Demand for Idle Money," Oxford Economic Papers, 2, 46-69.

[9] Craig, B., and Rocheteau, G., 2008a. "State-dependent pricing, inflation, and welfare in search economies," European Economic Review, 52, 441-468.

[10] Craig, B., and Rocheteau, G., 2008b. "Inflation and Welfare: A Search Approach," Journal of Money, Credit and Banking, 40, 89-119.

[11] Cynamon, B. Z., Dutkowsky, D. H., and Jones, B. E., 2006a. "Redefining the Monetary Aggregates: A Clean Sweep," Eastern Economic Journal, 32, 661-673.

[12] Cynamon, B. Z., Dutkowsky, D. H., and Jones, B. E., 2006b. "U.S. Narrow Money for the Twenty-first Century," Economic Inquiry, 44, 142-152.

[13] Drake, L., 1996. "Relative Prices in the UK Personal Sector Money Demand Function," Economic Journal, 106, 1209-1226.

[14] Dutkowsky, D. H., Cynamon, B. Z., 2003. "Sweep Programs: The Fall of M1 and the Rebirth of the Medium of Exchange," Journal of Money, Credit, and Banking, 35, 263-279.

[15] Ericsson, N. R., 1998. "Empirical Modeling of Money Demand," Empirical Economics, 23, 295315 .

[16] Faig, M., and Jerez, B., 2007. "Precautionary Balances and the Velocity of Circulation of Money," Journal of Money, Credit, and Banking, 39, 843-873. 
[17] Freeman, S., and Kydland, F. E., 2000. "Monetary Aggregates and Output," American Economic Review, 90, 1125-1135.

[18] Friedman, M., 1956. "The Quantity Theory of Money - A Restatement," In: Friedman M. (Ed.), Studies in the Quantity Theory of Money, University of Chicago Press, Chicago, 3-21.

[19] Friedman, M., and Schwartz, A. J., 1982. "Monetary Trends in the United States and the United Kingdom: Their Relation to Income, Prices, and Interest Rates, 1867-1975," Chicago University Press.

[20] Goldfeld, S. M., and Sichel, D. E., 1990. "The Demand for Money," in Friedman B. M. and Hahn F. H. (eds) Handbook of Monetary Economics, Volume I, Amsterdam: North-Holland, 299-356.

[21] Head, A., Liu, L. Q., Menzio, G., and Wright, R., 2012. "Sticky Prices: A New Monetarist Approach," Journal of the European Economic Association, 10, 939-973.

[22] Hendry, D. F., and Ericsson, N. R., 1991. "An Econometric Analysis of U.K. Money Demand in Monetary Trends in the United States and the United Kingdom by Milton Friedman and Anna J. Schwartz," American Economic Review, 81, 8-38.

[23] Hu, T., and Rocheteau, G., 2013. "On the Coexistence of Money and Higher Return Assets," Journal of Economic Theory, 148, 2520-2560.

[24] Ireland, P., 2009. "On the welfare cost of inflation and the recent behavior of money demand," American Economic Review, 99, 1040-1052.

[25] Ireland, P., 2015. "Comment on: On the stability of money demand, by Robert E. Lucas Jr. and Juan Pablo Nicolini," Journal of Monetary Economics, 73, 66-69.

[26] Judd, J. P., and Scadding, J. L, 1982. "The Search for a Stable Money Demand Function: A Survey of the Post-1973 Literature," Journal of Economic Literature, 20, 993-1023.

[27] Keynes, J. M., 1936. "The General Theory of Employment, Interest, and Money," London: Macmillan.

[28] Kiyotaki, N., and Wright, R., 1993. "A Search-theoretic Approach to Monetary Economics," American Economic Review, 83, 63-77.

[29] Lagos, R., and Rocheteau, G., 2008. "Money and Capital as Competing Media of Exchange," Journal of Economic Theory, 142, 247-258.

[30] Lagos, R., Rocheteau, G., and Wright, R., 2015. "Liquidity: A New Monetarist Perspective," Journal of Economic Literature, Forthcoming.

[31] Lagos, R., and Wright, R., 2005. "A Unified Framework for Monetary Theory and Policy Evaluation," Journal of Political Economy, 113, 463-484.

[32] Lester, B., Postlewaite, A., and Wright, R., 2012. "Liquidity, Information, Asset Prices and Monetary Policy," Review of Economic Studies, 79, 1209-1238. 
[33] Liu, L. Q., Wang, L., and Wright, R., 2015. "Costly Credit and Sticky Prices," University of Wisconsin, Working Paper.

[34] Lucas, R. E., 1988. "Money demand in the United States: A quantitative review," CarnegieRochester Conference Series on Public Policy, Elsevier, 29, 137-168.

[35] Lucas, R. E., 2000. "Inflation and Welfare," Econometrica, 68, 247-274.

[36] Lucas, R. E., and Nicolini, J. P., 2015. "On the Stability of Money Demand," Journal of Monetary Economics, 73, 48-65.

[37] Martins, J., Scarpetta, S., and Pilat, D., 1996. "Mark-Up Ratios in Manufacturing Industries: Estimates for 14 OECD Countries," OECD Economics Department Working Papers No. 162.

[38] Meltzer, A. H., 1963. "The Demand for Money: The Evidence from the Time Series," Journal of Political Economy, University of Chicago Press, 71, 219-246.

[39] Mogliani, M., and Urga, G., 2015. "On the Instability of Long-run Money Demand and the Welfare Cost of Inflation in the U.S.," Banque de France, Working Paper.

[40] Nosal, E., and Rocheteau, G., 2011. "Money, Payments, and Liquidity," MIT Press.

[41] Reynard, S., 2004. "Financial market participation and the apparent instability of money demand," Journal of Monetary Economics, 51, 1297-1317.

[42] Sargent, T. J., and Surico, P., 2011. "Two Illustrations of the Quantity Theory of Money: Breakdowns and Revivals," American Economic Review, 101, 109-128.

[43] Teles, P., Uhlig, H., and Valle Azevedo, J., 2015. "Is Quantity Theory Still Alive?," Economic Journal, Forthcoming.

[44] Teles, P., and Zhou, R., 2005. "A stable money demand: Looking for the right monetary aggregate," Federal Reserve Bank of Chicago Economic Perspectives, 29, 50-63.

[45] Tobin, J., 1956. "The Interest-Elasticity of the Transactions Demand for Cash," Review of Economics and Statistics, 38, 241-247.

[46] Wang, L., 2015. "Endogenous Search, Price Dispersion, and Welfare," University of Hawaii Manoa, Working Paper.

[47] Williamson, S., and Wright, R., 2010. "New Monetarist Economics: Models," in B. Friedman and M. Woodford (Eds.) Handbook of Monetary Economics, Volume II, Amsterdam: North-Holland. 